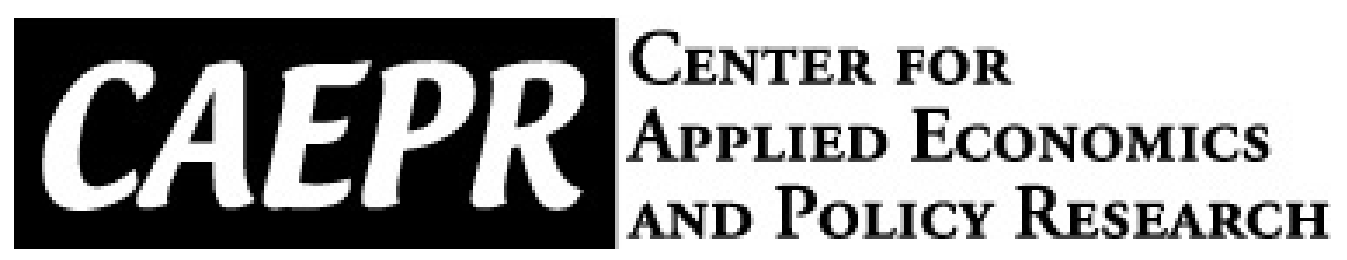

CAEPR Working Paper

\#005-2010

\title{
Cross Market Effects of stocks Short-Selling Restrictions: Evidence from the September 2008 Natural Experiment
}

\author{
Cristina Danciulescu \\ Indiana University
}

November 132009

This paper can be downloaded without charge from the Social Science Research Network electronic library at: http://ssrn.com/abstract=1597741.

The Center for Applied Economics and Policy Research resides in the Department of Economics at Indiana University Bloomington. CAEPR can be found on the Internet at:

http://www.indiana.edu/ caepr. CAEPR can be reached via email at caepr@indiana.edu or via phone at 812-855-4050.

(C2008 by NAME. All rights reserved. Short sections of text, not to exceed two paragraphs, may be quoted without explicit permission provided that full credit, including $\odot$ notice, is given to the source. 


\title{
Cross market effects of stocks short-selling restrictions: Evidence from the September 2008 natural experiment
}

\author{
Cristina Danciulescu \\ Indiana University Bloomington \\ This draft, November 13th, 2009
}

\begin{abstract}
Using intraday data, this paper investigates empirically the joint stock and corporate bond markets responses to the September 2008 stocks short sell ban. The study intends to exploit the natural experiment in order to asses the impact of the stock market short sale restrictions (stock market liquidity shock) on corporate bond market variables during the financial crisis period. The short sell ban was one of the levers that regulators pulled in order to manage the financial crisis. The economic question is whether this lever worked or should have been pulled given the complexity of financial market linkages and news dissemination. Recent financial events suggested that, when market conditions are severe, liquidity can rapidly decline or even disappear. Liquidity shocks are the potential channel through which asset prices are influenced by liquidity. However, the standard theoretical equilibrium asset pricing models do not consider trading and thus ignore the time and cost of transforming cash into financial assets and viceversa hence ignoring the impact of the liquidity shocks. Therefore, investigating liquidity shocks empirically, their transmission across markets is of high interest especially during times of high turbulence as we recently witnessed. We use vector autoregression (VAR) approach to model stock and corporate bond returns, volatilities and transaction costs simultaneously, obtaining an econometric reduced form that incorporates causal and feedback effects among the two markets variables. Using VAR tools, we found that shocks in stock market (short sell ban) had a significant negative impact on corporate bond market variables during the time under investigation.
\end{abstract}

Keywords and Phrases: Corporate bonds, Stocks, Short-sale restrictions, Cross markets effects JEL classification code: C12, C32, G01, G18.

12

\footnotetext{
${ }^{1}$ Corresponding author: Cristina Danciulescu, Department of Economics, Indiana University, Wylie Hall 105, $100 \mathrm{~S}$. Woodlawn, Bloomington, IN 47405. E-mail: cdanciul@indiana.edu.

${ }^{2} \mathrm{I}$ am indebted to Professor Craig Holden for his valuable advice, guidance and support during the formation of this paper. In addition, I would like to thank Professor Gregory Udell for valuable comments made on an investigation the author did to a similar event, Stacey Jacobsen and Chotibhak Jotikasthira for helpful conversations. All errors are mine.
} 


\section{Introduction}

What news or events move corporate bond market liquidity and prices? The answer to this question is of high interest to anyone monitoring the financial markets from traders and fund managers exploring buying and selling opportunities from price fluctuations, to central bankers using asset prices to manage investors' expectations.

Financial markets are driven by news and information. The standard asset pricing theory assumes that all market participants possess the same information. However, in reality different traders hold different information. Some traders might know more than others about the same event or they might hold information related to different events. Even if all the traders hear the same news in the form of a public announcement, they still might interpret it differently. Therefore, financial markets cannot be well understood unless one also examines the asymmetries in the information dispersion and assimilation process.

Depending on their information set, traders buy or sell assets. Informed agents' trading activities are motivated by private information about the real value of the assets not known to the other market participants. They act strategically in the attempt to make a profit out of this private information. On the other hand, traders who do not receive information are still conscious of the fact that the actions of the informed traders are driven by their information set and they try to infer the other traders' information. In consequence, the uninformed (liquidity) agents face the learning problem of inferring the true value of the traded assets by observing the behavior of the other traders. The usual way they learn is by looking at the market information such as prices, volumes and volatilities. In addition to a particular market information, comes all the available public information including other markets' variables and news released in those markets.

On September 18th 2008, the United States Securities and Exchange Commission (SEC) announced an Emergency Order restricting short sales in the stock market for 900 financial firms that included banks, insurance and securities firms, companies belonging to the highly leveraged financial sector. ${ }^{3}$ ${ }^{4}$ Our empirical investigation of the September 2008 stocks short sell ban focuses on the implications that such announcement and applied restrictions had for the corporate bond market. Does a short sell ban applied in the stock market have any impact on corporate bond market prices, volatility and liquidity? What are the potential channels through which a stocks short sell ban could influence the

\footnotetext{
${ }^{3}$ A short sell ban means that traders are no longer allowed to sell a stock that they do not own, known as "shorting" the stock, even if they are able to locate someone who does and is willing to lend it.

${ }^{4}$ However SEC issued an exemption to this ban for the registered market makers who were facilitating client orders. Without this exemption, market makers would not have been able to hedge their exposure and may have forced clients to pay much higher prices in order to take on the unhedged risk.
} 
corporate bond market variables? How fast is the new information related to the ban incorporated into the corporate bonds prices? Do short sell restrictions in the stock market move the pessimist investors from the stock market into the corporate bond market? What are the cross market effects of announcing and imposing such restrictions during abnormal periods as for example a financial turbulence? Is there any empirical evidence that these two markets are integrated? These are the main empirical questions that we intend to address in this paper.

In order to motivate our proposal of joint consideration in analysis of both markets, we provide an intuition that relies on the bond price determination theory. According to this theory, a bond price equals the present value of all future cash flows from the asset discounted at a certain discount rate. More formally, the time $t$ price of a $n$-period bond $B$ equals the discounted sum of all future coupon payments and the face value of the bond:

$$
B(T)=E\left\{\sum_{t=1}^{T} \frac{C_{t}}{[1+Y(T)]^{t}}+\frac{F V_{t}}{[1+Y(T)]^{T}}\right\},
$$

where $B(T)$ is the price of the coupon bond maturing at date $T, C_{t}$ is the dollar amount of coupon payments at date $t, F V_{t}$ is the dollar amount of face value at time $t$, and $Y(T)$ denotes the "yield-tomaturity" of the coupon bond maturing at date $T$.

By Fisher decomposition and the Expectation hypothesis we have that the interest rate at time $t$ on the $n$ period nominal bond, $Y_{t}^{n}$, can be decomposed into a real interest rate component and an average expected inflation component

$$
Y_{t}^{n}=E\left(R^{n} \mid I_{t}\right)+E\left(\pi^{n} \mid I_{t}\right)
$$

where $Y_{t}^{n}$ denotes the $n$-period nominal yield, $E\left(R^{n} \mid I_{t}\right)$ is the real interest rate and $E\left(\pi^{n} \mid I_{t}\right)$ is the inflation expected to prevail over the $n$ periods given the information set at time $t, I_{t}$. The above relationships imply that any change in bond yields and bond prices are by definition caused by changes in the information set $I_{t}$. Therefore, news can cause revisions to what is currently built into the corporate bond prices. ${ }^{5}$ More specific to our paper's topic, news about a short sell ban in the stock market could cause corporate bond market participants to revise their expectations, and this could be reflected in higher corporate bond market volatility compared with a period free of such event. This theoretical result motivated us to explore empirically the effects that such event implied for the corporate bond market variables: returns, volatility and liquidity.

\footnotetext{
${ }^{5}$ Ederington and Lee (1993) reported that macro announcements seem to be responsible for most of the volatilities in the bond markets.
} 
This research contributes to the existing literature in a number of ways. First, this paper examines jointly the stock and corporate bond markets dynamic properties. In the market microstructure literature, there are some recent papers, as for example Chordia et al. (2005), Goyenko et al. (2009 a and b), that analyzed the joint stock and bond markets dynamics. However their research investigated joint dynamics of stocks and treasury, having as underlying motivation a "flight-to-quality" phenomenon. ${ }^{6}$ This is not our case framework since both assets considered are risky. Second, it examines the corporate bond market reactions to a short sell ban in the stocks market, a topic that did not receive attention so far in the theoretical and empirical short selling literature. Moreover it investigates the relationship between these two markets and reactions to the ban during the 2008 financial crisis, an important topic since relationships among different assets and financial markets may be very different during financial turbulence periods versus the normal times. The liquidity behavior during a financial crisis, for example, a subject of high interest for financial market participants and regulators, may be very different compared to the one from the normal periods. In this respect, our empirical study may potentially be of high interest to anyone who monitors financial markets since investors may behave in an unusual manner at certain points during a business cycle, as for example a recession or financial downturn. Market participants may perceive, at least temporary, that some macroeconomic announcements, as for example a short sell ban, is more important than others which in turn will lead to heightened attention being paid to the respective news. Therefore it is reasonable to assume different market reactions depending on the state of the business cycle. Since the short sell ban was one of the levers that regulators pulled to manage the 2008 financial crisis, this study allows us to shed some light on the un-addressed in the literature but significant economic question on whether this lever worked or should be pulled.

We model volatilities, returns and transaction costs of equity and corporate bond markets simultaneously using the vector autoregression method (VAR). ${ }^{7}$ VAR method is in particular suitable for our investigation because it allows an explicit comparison of liquidity and other markets variables of interest across different macroeconomic regimes. This method allows one variable to depend on the current and lagged values of other variables under study building a system that incorporates causal and feedback effects among the two markets variables. Moreover, the econometric methodology proposed in this paper is suitable for studying the long-run equilibrium properties of two markets in which

\footnotetext{
${ }^{6}$ Flight-to-quality means the action of investors moving their capital away from riskier investments to the safest possible investment vehicles. This flight is usually caused by uncertainty in the financial markets.

${ }^{7}$ VAR method was pioneered in market microstructure analysis by Hasbrouck (1995). Recent papers that modeled simultaneously different markets using VAR method are Chordia, Sarkar and Subrahmanyam (2005), Goyenko et al. (2009 a and b).
} 
assets are traded with different frequencies. ${ }^{8}$ In this modeling framework we can explicitly deal with questions related to the information contained in prices, how information is assimilated across the two markets, the behavior of transaction prices and how the spreads respond to the same market generated as well as other markets or/and public information. We construct impulse-response functions that show how the system reacts to a perturbation to its long-run equilibrium. Impulse response analysis is, also, useful for documenting market resilience i.e. the speed with which market variables tend to converge back to the initial equilibrium after a perturbation to the system. In addition, we are able to investigate causality issues among the two markets' variables by running Granger-causality tests, and construct markets' predictions at different horizons using forecast error variance decomposition tool.

Our empirical findings point to a deterioration in both stock and corporate bond markets quality for the firms that were subject to September 2008 short sell restrictions. The short sell ban had a negative impact for the liquidity in the stock and corporate bond markets as bid-ask spreads widened, increased the volatility in both markets, and price in the corporate bond market revealed a decreasing trend. This last fact coupled with a substantial increase in the corporate bonds volume for the firms subject to the ban suggested the possibility that short selling strategy might had been intensified in the corporate bond market after the ban, potentially due to moving some pessimists from the stock market into the Over-the-Counter (OTC) market. In this respect, our results have some policy implications, supporting an integrated view regarding future regulatory measures. For financial markets law-makers and regulators, it suggests that future regulatory measures should consider simultaneous actions in both markets.

The remainder of the paper is structured as follows. Section 2 reviews the short selling literature and discusses our contribution to this literature. Section 3 describes our empirical hypotheses. Section 4 presents data and defines the system's variables. Section 5 describes the transaction costs' calculations for the two markets. Section 6 reviews the VAR method used. The main results are discussed in section 7 . Section 8 concludes.

\section{Literature Review}

Tough there is an extensive literature that analyzes the stock market effects of restricting short selling strategies for stocks, none of the papers investigated so far either at the theoretical or empirical level how these restrictions impact the corporate bond market, meaning if there are some spillover effects

\footnotetext{
${ }^{8}$ Manganelli (2005) investigated this topic using only stock market data.
} 
from announcements and restrictions applied in the stock market into the corporate bond market. This potentially might have happened due to the fact that, unlike the stock market, only recently the corporate bond market became transparent. ${ }^{9} 10$

The prior short selling research focused on the effects that such measure had for the stocks market quality, or made comparisons across countries that experienced a ban versus the ones that did not experience such measures in the stock market. The academic literature provided evidence supporting the fact that short sale constraints, regulatory restrictions reduce the efficient pricing of assets, especially in times of negative news.

At the theoretical level, a referential paper is Miller (1977). He advanced the idea that, in a market with little or no short selling, the demand for a particular security will come from the minority who holds the most optimistic expectation about it, and since divergence of opinions is likely to increase with risk, it is possible that expected returns will be lower for risky securities rather than higher.

Diamond and Verechia (1987) investigated the effects of short sale constraints on the speed of price-adjustment to private information. Their model predicted that, in the presence of short sale constraints, information has an asymmetric impact on asset prices meaning that the short sell constraints result in a different dissemination of positive and negative information.

Work by Abrew and Brunnermeier (2002), Andersen (2008), Brunnermeier and Pedersen (2008) showed that short sale constraints can lead to bubbles and excessive volatility.

Lamont (2004) examined the effects of short sales and market frictions on the efficiency of price discovery for a sample of firms that took legal and regulatory actions to impede the short sales of their stocks. He found that firms which took these actions underperformed in the year subsequent to the legal and regulatory action, a result consistent with the hypothesis that short sales constraints facilitate stock overpricing resulting in low expected returns.

Charoenrook and Daouk (2005) made the first step in investigating the effects of imposing short sell restrictions across markets by comparing the stock market variables of countries in which this strategy was restricted versus the ones where it was not. They analyzed historical short selling data, put option trading regulations and practices for 111 countries. The authors concluded that the way the liquidity will evolve in the restricted markets will depend on which effect dominates: investors' trading activity determined by market returns or inventory concerns determined by volatility. Charoenrook and Daouk (2005) found that when short selling is possible, aggregate stock returns are less volatile,

\footnotetext{
${ }^{9}$ For the detailed information regarding Trade Reporting and Compliance Engine (TRACE) system implementation see www.nasd.com.

${ }^{10}$ See Bessembinder et al. (2005, 2006), Edwards et al. (2007) for the effects TRACE implementation had on corporate bond market quality.
} 
there is greater liquidity, and the overall market quality improves. They did not find any evidence that short-sale restrictions increase the probability of a market crash. ${ }^{11}$

\section{Empirical Hypotheses}

In this section we will address several specific empirical questions and formulate the hypotheses regarding the effects of the short sell restrictions applied in the stock market for the corporate bond market variables. For each of these questions, we will first discuss the theoretical background and then derive the testable implications.

A very popular class of models in the market microstructure literature is the asymmetric information one. ${ }^{12} 13$ These models examine market dynamics subject to a single source of uncertainty, that is, a single information event. However in the actual securities markets, information often arrive in a lumpy fashion. Long periods with no new information and steady or sluggish trading are punctuated by periods of extremely active trading before, during, and after major news announcements. These models' general implication is that market activity and volatility change over time because new information becomes available to traders at a varying rate, therefore volume and volatility influence prices because they are correlated with private information about the securities' true value.

A different group of models, which is the sequential market trade group, makes a step further by establishing a connection between information asymmetries and observable market phenomena. The simple sequential trade model of Glosten and Milgrom (1985), for example, posits that the proportion of informed traders in the population is positively related to both bid-ask spread and the revisions in beliefs. These results suggest using the bid-ask spread or the impact an order has on subsequent prices as proxies for the asymmetric information.

Recent microstructure research proposed a multi market simultaneous analysis for better modeling and understanding of the financial markets linkages. ${ }^{14}$ Other markets variables could help explain a particular security dynamics since markets for different securities often interact. These other variables include orders, trades and prices of related securities. By considering other markets relevant variables

\footnotetext{
${ }^{11}$ Research on the stock short sell restrictions subject is more extensive, but the focus is on other issues than the ones we investigate in this paper: cross markets effects. For an extended review of this literature, readers can refer to work by Bris, Goetzmann, and Zhu (2004), Shkilko, Bonnie Van Ness, and Robert Van Ness (2007), Daske, Richardson, and Tuna (2005), Diether, Lee and Werner (2005), Chen and Singal (2001), Hong and Stein (2003).

${ }^{12}$ The referential paper is Bagehot (1971).

${ }^{13}$ There is an extensive literature that built on this idea as for example Kyle (1985), Glosten and Milgrom (1985), Easley and O'Hara (1987, 1992), O'Hara (1995), Diamond and Verrechia (1987), Admati and Pfleiderer (1988).

${ }^{14}$ For example, Chordia et al. (2001) and Goyenko et al. (2009) showed that stocks and bonds (treasury) liquidities comove. Also, Brunnermeier and Pedersen (2008), Chordia et al. (2005) suggested that macroeconomic variables and stock price volatility may impact bond market liquidity by affecting market-making costs.
} 
we obtain multivariate models that, under certain circumstances, can identify price changes with a particular source of information. ${ }^{15}$ Relying on different securities interaction hypothesis Huang and Stoll (1997), for example, based their three-way decomposition of a stock spread on the fact that inventory-induced quote changes result not only from inventory changes in the stock being examined but, also, from inventory changes in other stocks. Their approach assumed that inventory effects relate to the entire portfolios held by the suppliers of the liquidity. Huang and Stoll (1997) hypothesis was that a liquidity supplier who buys a stock at the bid will not only lower the bid and ask prices of the respective stock, but will also lower the bid and ask prices of other correlated stocks. The portfolio approach analysis allows for the possibility that quotes in a security be adjusted by a different amount than the one implied by the information content or inventory effect only for the respective stock. Selling and buying pressure in other securities will produce quote changes in the respective stock as the liquidity suppliers attempt to keep their overall portfolio in balance. Huang and Stoll (1997) noted that this type of adjustments were obvious during October 1987 market crash event, when relentless selling pressure in the absence of any specific news produced inventory-induced quote changes in specific stocks. The authors provided, also, a motivation for considering the empirical analysis of different securities jointly using an econometric method that accounts for correlations across securities (as our proposed VAR method does). Because all securities respond to marketwide public information, and the public information shocks could be contemporaneously correlated across securities, they claim that, by modeling simultaneously $n$ securities, we may get a more efficient estimation.

In our particular equity and corporate bond markets framework, the theoretical explanation goes back to Merton (1974). He showed that both equity and corporate bond are derivatives of the same firm's value, therefore it should be a relationship between the values of these two securities, and between the equity and corporate bond markets. In practice, also, a number of asset allocation strategies shift wealth between the stock and corporate bond markets so the trading processes may reflect these long-term interactions and may exhibit other dependencies as well. Consequently, trades across these two markets may be correlated, also, for non-informational issues as for example optimal portfolio choices and arbitrage.

Our first question and empirical hypothesis is based on Holden (1995) theoretical model. The underlying model assumption was that information flows may differ in security markets that trade at different frequencies, leading to divergence in market prices and introducing the possibility of arbitrage between markets. ${ }^{16}$ Holden (1995) built a model in which arbitrageurs optimally exploit arbitrage

\footnotetext{
${ }^{15}$ See Hamilton (1994) ch. 10 and 11 for the general modeling aspects, and Hasbrouck (1988, 1991 a and b, 1993) for microstructure applications.

${ }^{16}$ See also Manganelli (2005).
} 
opportunities between the markets for two securities: stock (stock index portfolio) and "synthetic stocks" (stock index futures and bonds). With different liquidity shocks in each market, there are different realized prices (or liquidity premia) in each market. In Holden (1995) model, the arbitrage trading connects the two markets and reduce the price difference between the two securities. ${ }^{17} 18$ Holden (1995) examines the effects of the arbitrage trading on markets' volatilities, liquidities and the hedging effectiveness of the synthetic securities as measured by intermarket price correlation. He made a comparison between a restricted economy where arbitrage is prohibited and an unrestricted economy where arbitrage is permitted, and showed that permitting arbitrage causes no net change in volatility, an increase in the liquidity of the markets, and an increase in the hedging effectiveness of the synthetic securities. ${ }^{19}$

Question No. 1: What are the effects of a liquidity shock in the stock market for the corporate bond market liquidity, returns and volatility?

This question implies the investigation of several related questions as following:

Are liquidity shocks in the stock market transmitted into the corporate bond market? Does stock market liquidity forecast returns in the corporate bond market? In other words, do liquidity level in the stock market provide any information about the future liquidity and liquidity premia in the corporate bond market?

In our empirical framework, we assumed that the liquidity shock in the stock market is the imposed short sell ban. Our first hypothesis is the testable implication of Holden (1995) model:

H1: After imposing short sale restrictions in the stock market (a liquidity shock in the stock market), we hypothesize that liquidity in the stock and corporate bond markets will decrease. Moreover, we expect volatility in both markets to remain the same.

Market liquidity is a fundamental concept in finance and it refers to the ability of buying or selling

\footnotetext{
${ }^{17}$ Within the same line of research, Subrahmanyam (1991) built a model that showed how the introduction of a basket of securities had implications for the informativeness and variability of prices, and market liquidity. He characterized the strategic trading decision of liquidity traders that may trade either in individual securities or portfolios, and examined the "lead-lag" relationships between these, which means that the tendency for movements in one price provides predictive information about subsequent movements in another price. Subrahmanyam (1991) showed that movements in both the price of the individual security and the price of the basket provide information about the subsequent movements in the price of the other.

${ }^{18}$ See, also, Kumar and Seppi (1989) for research in the same thread.

${ }^{19}$ Grossman and Miller (1988) claimed that arbitrageurs, by taking offsetting positions in different markets simultaneously, can smooth the pressure of order imbalances from one market to the other, therefore price concession and the cost of transacting are kept smaller in both markets due to arbitrage trading. Their opinion was that the effective market-making capacity during and in the period immediately after the October 1987 crash was reduced by imposing restrictions on "program trading" which cut the arbitrage.
} 
large quantities of assets quickly and at a low cost. Market liquidity is high when it is easy to raise money by selling the asset instead of borrowing against it, meaning that it is high when selling the asset does not depress the sale price too much. Everybody who stands ready to take on the other side of a trade provides market liquidity. These include opportunistic traders or potential investors who are ready to jump in whenever selling/buying pressures cause a temporary price decrease/rise. Large price movements will occur when several traders attempt to get out of the identical positions at the same time.

Our second question relates to a different understanding of the market liquidity concept than the one stated above, which is market resilience. As Kyle (1985) noted, "market liquidity" is a slippery and elusive concept, in part because it encompasses a number of transactional properties of the markets. These include "tightness" (the cost of turning around a position over a short period of time), "depth" (the size of an order flow innovation required to change prices a given amount), and "resiliency" ( the speed with which prices recover from a random, uninformative shock). ${ }^{20}$ Our second hypothesis refers to the "resiliency" understanding of the market liquidity concept which means: if the price drops temporarily how long it will take to bounce back?

From the liquidity perspective, multimarket linkages introduce complex, and often conflicting effects on market liquidity. While portfolio rebalance motives and arbitrage would ultimately draw the markets together, their immediate impact is to increase the bid-ask spread in both markets, thus reducing the liquidity in both. With respect to the market resilience concept, we formulate our second question as following:

Question No. 2: What are the effects of a liquidity shock in stock market for the stock and corporate bond markets' resilience?

Our second hypothesis regarding the market resilience is the following:

H2: A short sell restriction in the stock market increases market resilience in the stock market and decreases market resilience in the corporate bond market.

Many market microstructure models showed that, in the limit, prices converge to their full information values, but they do not give any information about the speed or time this adjustment process takes, and how exactly this convergence is impacted by multimarket considerations. Subrahmanyam (1991) suggested that, if agents have symmetric access to both systematic and idiosyncratic infor-

\footnotetext{
${ }^{20}$ Black defined a liquid market as one which is almost infinitely tight, which is not infinitely deep, and which is resilient enough so that prices eventually tend to their underlying value.
} 
mation, then neither market can act as a dominant price discovery market. However agents in the "price discovery" literature may find prices in some market more informative about the true value of the asset traded in the respective market than prices in other markets. Differential learning that divergent prices permit to the market participants may have an effect on the speed of convergence to the assets' full information values for different markets.

Manganelli (2005) took the first step in investigating empirically the differences in the speed of convergence for securities belonging to the same market. Using a sample of 10 stocks separated in two groups according to their trading intensity, he found that price variance of more frequently traded stocks converges more rapidly to the long-run equilibrium after an initial perturbation. Our third question extends Manganelli (2005) investigation from stock market to multimarket considerations. We investigate the speed of convergence to the full information value for the variables in the corporate bond market after a stock market perturbation (short sell ban). In this respect, useful tools for this kind of analysis are VAR's impulse response functions.

Question No. 3: How long does it take for the new information regarding the short sell ban in the stock market to be impounded into the corporate bond prices?

Our testable implication for the third question is:

H3: Volatility of corporate bonds, which are less frequently traded securities than stocks, should converge less rapidly than volatility of stocks to their long run equilibrium after an initial perturbation in the stock market.

Theoretical models with differences in beliefs predict that short sales constrains should cause stock prices to rise and become overvalued. In these models, shorting restrictions eliminate the pessimist investors from the market, and optimist investors do not take into account the absence of pessimists in setting prices. Supposing that the pessimistic investors actively manage a portfolio of stocks and bonds, we expect that, being restricted to short sell in the stock market, these investors will move the short selling activities from the restricted stock market into the unrestricted corporate bond market.

Moreover, recent work by Berkovitz et al. (2009) pointed out toward a growing empirical literature which argues that short sellers are informed traders because short interest is predictive of negative abnormal returns. The literature argues that short sellers appear to earn substantial abnormal trading profits due to their superior analytical skills. Using data for 26 banks that covered the 2008 financial crisis period, Berkovitz et al. (2009) found evidence consistent with the view that informed short sellers stepped in to take advantage of the high levels of uncertainty by trading on information regarding the 
potential effects of the financial institutions' default risk.

From the perspective of the liquidity traders a conjecture that was not addressed so far in the microstructure models but it is often stated, is that liquidity traders prefer less volatile markets. According to Admati and Pfleiderer (1988), they prefer to trade when the market is "thick", that is when their trading has little impact on prices, creating a concentration of trading activity. On the other hand, informed traders, also, want to trade when the market is thick. Consequently, liquidity could be enhanced in a less volatile market by simply adding more market participants willing to trade. In our stock short sell ban context, this will imply that liquidity in the corporate bond market would increase due to the increased number of market participants willing to trade in the unrestricted market.

Our fourth question is related to the short selling theoretical models' implication which is eliminating the pessimist investors, mostly informed investors according to the literature, from the stock market. Given a specific trading mechanism, it may be possible to investigate the effects of multiple informed traders on market behavior. This is the approach taken in Holden and Subrahmanyam (1992), who developed a multi-period auction model in which multiple privately informed agents strategically exploit their long-lived information.

Holden and Subrahmanyam (1992) showed that, in contrast to Kyle's results, the informed traders tend to trade more aggressively than their monopolist counterpart. In the limit, as the number of informed traders goes to infinity, all their private information is revealed immediately. The same result holds with just two informed traders, as the number of auctions (trades) increases and tends to infinity. Holden and Subrahmanyam (1992) illustrated the difference between the imperfectly competitive case and the monopolistic case with a series of numerical simulations. Their simulations showed that price variance and market liquidity parameter decline very rapidly to zero through time as the number of informed traders or the number of auctions increase. Our fourth question and hypothesis is the testable implication of Holden and Subrahmanyam (1992) theoretical model in the short sell ban context.

Question No. 4: Do pessimist investors switch from the stock market into the corporate bond market after imposing a short sell ban in the stock market?

The question can be reformulated to a more testable version:

Does a short sell ban in the stock market result in a greater activity in the corporate bond market due to potentially a higher number of informed traders who switch from the stock market into the corporate bond market?

Our testable implication of Holden and Subrahmanyam (1992) model is the following: 
H4: A short sell ban in the stock market has as effect an increase in the corporate bond market volume and price variance.

Therefore, we hypothesize that, in our short sell ban context, the pessimist investors, being restricted to short sell in the stock market, switch into the corporate bond market, and this result in an increase in the number of traders and trading intensity.

\section{Data and Variables}

We use tick-by-tick stock data from Trades and Quotes (TAQ) database and corporate bond data from Trade Reporting and Compliance Engine (TRACE) system for the 900 financial firms on which the stock short sell ban was imposed in September 2008. The data are read from the TAQ and TRACE data files on Wharton Research Data Services (WRDS) using the remote processing SAS/CONNECT software and cover the period from May 1st to September 30th, 2008.

The major problem while using TAQ data for stock spread calculations is that Trades and Quotes are recorded in two different files and one needs first to reconstruct the trading activity timeline. From TAQ Consolidated Trades data we get the actual trade price per share and the number of shares traded while from TAQ Consolidated Quotes we get the bid and offer prices. Therefore, in order to obtain an as accurate as possible path of the actual trading activity and get an as accurate as possible measures of stock market spreads, a crucial step is merging trades and quotes in an appropriate manner that reflects the time when each occurred.

Merging Trades and Quotes files has to be done with care accounting for several problems acknowledged by the empirical market microstructure research. One problem is that trades and quotes updates take place at different times. Usually quotes are updated after a trade takes place. Another known problem is that the time stamps on trades and quotes are systematically different. The main reason is that quotes are entered into the system by the specialist, while trades are entered by the exchange clerks. Because his trading profits are at stake, the specialist will usually enter the quotes in a very timely manner. In contrast, data executed on trades serve primarily an accounting purpose, and the immediate recording is not essential as for the quotes. As a result, trades are typically entered with a delay, mostly ranging between 5 and 15 seconds. Moreover, because reported trades represent matches of buyers and sellers at a certain price, trade direction cannot be observed directly. Therefore we need to employ a method to identify if the trade is a buyer or a seller initiated trade. 
The two commonly used procedures to infer trade direction from trades and quotes data are the tick test and the quote test. ${ }^{21}$ The tick test classifies a trade as buyer-initiated if the trade price is above the previous price. Correspondingly, when the current price is below the previous one the trade is classified as seller-initiated. The quote test compares the current price to the prevailing quotes. If the transaction takes place above the quotes midpoint, it is considered to be buyer-initiated while if it is below the midpoint it is considered to be seller-initiated. For this paper, we computed both measures, and, as suggested by Lee and Ready (1991), use a combination of them to infer trade direction.

We obtained the data set necessary to calculate the stock transaction costs by the following steps. In a preliminary step, we combined all trades that took place at the same second and price. The underlying intuition is that these individually reported trades are in fact part of the same order, and therefore should be combined (by summing the number of shares). The next preliminary step was to correct the time stamps which means to correct the reporting delay associated with the trade time (five seconds delay), and compute the tick test. Then we computed the quote changes that also affected the quote midpoint and we combined the trades and quotes. In order to estimate the transaction costs measures we need to identify the quotes that were posted at the time a trade was executed. From the merged data set, the most recent quote record that precedes a certain trade is the prevailing quote for the respective trade.

The stock intraday data were purged for the following reasons: trades out of sequence, trades recorded before the opening, 9:30 a.m., or after the closing time, 16:00 p.m., and trades with special settlement conditions (because they might be subject to distinct liquidity considerations). Negative bid-ask spread quotations, transaction prices, and quoted depths were discarded. Following Lee and Ready (1991), any quote less than five seconds prior to the trade is ignored and the first one at least five seconds prior to the trade is retained.

The TRACE data set includes all reported Over-the-Counter (OTC) trades in corporate bonds. Data items include price, dollar quantity of the transaction, yield and the side (or sides for interdealer transactions) on which the dealer participated. Same as in the case of TAQ data, we dropped any transaction that occurred before opening time, 9:30 a.m., and after the closing time, 16:00 p.m..

Due to the fact that TRACE database does not contain information about bids and asks, we need to estimate corporate bond transaction costs using an econometric model. Consequently we have to use some data that allow us to control for the fundamental bonds' values. We obtain data on stock returns, risk-free interest rate, BBB-AAA credit spreads, and VIX index. ${ }^{22}$ We use TAQ database for

${ }^{21}$ See Lee and Ready (1991).

${ }^{22}$ VIX is the ticker symbol for the Chicago Board Options Exchange Volatility Index, a popular measure of the 
the individual stock prices and the Center for Research in Security Prices (CRSP) database for the market index. We use the Federal Reserve's (FED) constant-maturity Treasury bond yields for the risk-free interest rates. The BBB and AAA bond yields are obtained from the FED's website, and the VIX data from the Chicago Board Options Exchange (CBOE) website.

The variables to be included in the vector autoregression are returns from both markets, volatilities and transaction costs. The way we calculated the daily aggregate values for the variables to be included in the VAR, was first by computing from tick data the equal-weighted average of each variable for each security, and then obtaining the equal-weighted average across all securities for each day. The returns are computed as the difference in log prices.

\section{Transaction Costs Calculations}

\subsection{Stocks Transaction Costs Calculation}

For the stock transaction cost variable we calculated quoted spread as

$$
\text { quotedspread }=\frac{A s k-B i d}{\frac{1}{2}(A s k+B i d)},
$$

where Ask and Bid are intraday stock quoted ask and bid prices.

Alternatively, one can use the stock effective spread which is calculated as twice the absolute value of the difference between trade price and the midpoint of the prevailing bid-ask quote.

\subsection{Corporate Bonds Transaction Costs Estimation Method}

As Edwards et al. (2007) pointed out, corporate bond data present two challenges for the transaction costs measurement. First, since quotation data do not exist for the corporate bond market ${ }^{23}$, we cannot estimate transaction costs for each corporate bond trade using transaction methods based on benchmark prices such as the quoted or effective spreads. Instead we need to estimate the transaction costs using an econometric model. The second problem relates to the scarcity of data for many bonds. Since the econometric model does not benefit from information in contemporaneous observable benchmark prices, our results are less precise than if such information were available.

We employ Huang and Stoll (1997) indicator variable model as extended by Bessembinder et al. (2005) for estimating corporate bond transaction costs. In what is following we will briefly introduce

implied volatility of S\&P 500 index options. A high value corresponds to a more volatile market and therefore more costly options, which can be used to defray risk from this volatility by selling options. Often referred to as the fear index, it represents one measure of the market's expectation of volatility over the next 30 day period.

${ }^{23}$ TRACE does not have quotation data. 
Bessembinder et al. (2005) model.

Let $S_{t}$ denote the effective round trip spread, meaning the difference between the price at which dealers will sell a bond and the price at which they will purchase the bond at time $t$. Let $P_{t}$ denote the transaction price at time $t, V_{t}$ denote the unobservable true value of the bond at time $t$, and let $Q_{t}$ be an indicator variable that equals 1 if the time $t$ trade is a customer buy, -1 if it is a customer sell, and 0 if it is an interdealer trade.

Innovations in the underlying value of the bond are attributable to public information releases and, potentially, private information revealed through buy or sell orders:

$$
V_{t}=V_{t-1}+\gamma Q_{t-1}+\varepsilon_{t},
$$

where $\gamma$ reflects the private information content of a buy or sell order and $\varepsilon_{t}$ represents new public information. We assume that a fraction $w$ of the public information eventually becomes observable to econometricians in the form of data with realizations $X_{t}$, while the remaining portion is due to unobservable innovations $U_{t}$ that represent statistical noise:

$$
\varepsilon_{t}=w X_{t}+(1-w) U_{t}
$$

Assuming that the spread is symmetric, customers buy (sell) at a price that exceeds (is less than) the underlying bond value by half the effective spread:

$$
P_{t}=V_{t}+Q_{t}\left(\frac{S_{t}}{2}\right) .
$$

Let $\Delta$ denote the difference between the observation at date $t$ and the preceding observation, then the first differences of the previous three expressions can be combined to give:

$$
\Delta P_{t}=w \Delta X_{t}+\gamma Q_{t-1}+\left(\frac{S_{t}}{2}\right) \Delta Q_{t}+(1-w) \Delta U_{t} .
$$

The last two expressions suggest that the half spread can be estimated by appropriately specified regressions of observed (changes in) prices on (changes in) buy-sell indicator variables.

Based on the last equation, we estimate regressions of the form

$$
\Delta P_{t}=a+w \Delta X_{t}+\gamma Q_{t-1}+\left(\frac{S_{t}}{2}\right) \Delta Q_{t}+\eta_{t} .
$$

The specification is identical to the regression equation 5 in Huang and Stoll (1997) with the exception that Bessembinder et al. (2005) allows for the effect of observable public information on 
the underlying bond value. The authors claim that the inclusion of public information is potentially important for corporate bonds since the elapsed time between trades can be long. We assumed, as the authors, the spread to be symmetric or, equivalently, that the dealer inventory cost do not affect dealer reservation prices.

Furthermore, suppose that the spread for trade $t$ depends on the variable $Z_{t}$ according to the relationship:

$$
\frac{S_{t}}{2}=b_{0}+b_{1} Z_{t}^{*}
$$

where the $*$ denotes the fact that the variable $Z_{t}$ is expressed as deviations from its own time series mean.

Substituting the last equation in the previous one gives an expanded indicator regression model:

$$
\Delta P_{t}=a+w \Delta X_{t}+\gamma Q_{t-1}+b_{0} \Delta Q_{t}+b_{1} Z_{t}^{*} \Delta Q_{t}+\eta_{t}
$$

In the last expression, the coefficient $b_{0}$ estimates the half-spread conditional on a specific outcome on the explanatory variable $Z_{t}$, while the coefficient $b_{1}$ estimates the effect of variable $Z_{t}$ on the halfspread. The candidates for inclusion in $Z_{t}$ should be variables that plausibly affect the cost of corporate bond market making. For example, Demsetz (1968) had argued that increased trading volume should reduce bid-ask spreads. Therefore we opted, following Edwards et al (2006) and Bessembinder et al. (2005), for the selection of the dollar trading volume as the $Z_{t}$ variable.

\section{Econometric Method for Investigating Cross Markets Ef- fects}

In this section we discuss the econometric procedure used to investigate cross market effects, which is vector autoregressive method (VAR). We review briefly the method and the test statistics that is used to evaluate if there is any relationship across markets during the investigated period.

Vector autoregression method (VAR) is one of the most widely used method in empirical finance. The underlying assumption in VAR analysis is that the evolution of the endogenous variables of interest can be represented by a set of simultaneous linear equations $y_{t}$ with $y_{t}=\left[y_{1, t}, \ldots y_{k, t}\right]^{\prime}$ where $k=2$ in our case, with each variables having feedback from its own lags and other variables lags. All VAR equations include lags up to a maximum of order $p$ where $p$ is determined, in our case, using Akaike information criterion (AIC). 
The joint dynamics of the endogenous variables for the two markets is modeled using the reduced form VAR:

$$
y_{t}=c_{t}+\Phi_{1} y_{t-1}+\Phi_{2} y_{t-2}+\ldots+\Phi_{p} y_{t-p}+\varepsilon_{t},
$$

where $c_{t}$ is the vectors of deterministic terms, and $\varepsilon_{t}$ are the error terms that are assumed to have a non-diagonal variance-covariance matrix $E\left[u_{t} u_{t}^{\prime}\right]=\Sigma$. We assume that the error terms are serially uncorrelated across markets.

In what is following we present shortly the main VAR tools that we employ: impulse responses, variance decomposition and Granger causality test.

In the applied VAR literature it is very rare to report VAR coefficients. Since the number of parameters is large, presenting all of them is cumbersome. Furthermore, they are poorly estimated: except for the first own lag, they are usually all insignificant. It is therefore wide practice to report functions of the VAR coefficients which summarizes information better, have some economic meaning, and are potentially more precisely estimated. Among the many possible functions two are the most used: impulse response functions and variance decomposition.

Impulse responses trace out the moving average (MA) of the system, i.e. they describe how $y_{i, t+\tau}$ responds to a shock in $e_{i, t}^{\prime}$. The main purpose of the impulse response functions is to identify structural shocks. Calculation of meaningful impulse responses requires orthogonal disturbances, meaning that they are mutually uncorrelated and have a diagonal variance covariance matrix $E\left[u_{t} u_{t}^{\prime}\right]=D$, which in our case will be market specific.

In order to identify responses of the endogenous variables $y_{t}$ to the structural shocks, we need to find a matrix $A$ such that $A u_{t}=\varepsilon_{t}$, hence $\Sigma=A D A^{\prime}$. If each $A$ is a full-rank $n \times n$ matrix, then we can define as an impulse response vector any column $a$ of this matrix $A$.

We calculate the impulse response functions using the nonrecursive (companion) form approach. We stack the equations as

$$
Y_{t}=\Phi Y_{t-1}+U_{t}
$$

where $Y_{t}=\left[y_{t}, y_{t-1} \ldots, y_{t-p+1}\right]^{\prime}, U_{k}=\left[u_{t}, 0, \ldots, 0\right]^{\prime}$, and

$$
\Phi=\left(\begin{array}{ccccc}
\Phi_{1} & \Phi_{2} & \ldots & \Phi_{p-1} & \Phi_{p} \\
I_{n} & 0 & \ldots & 0 & 0 \\
0 & I_{n} & \ldots & 0 & 0 \\
0 & 0 & \ldots & I_{n} & 0
\end{array}\right)
$$

The first $k$ rows of the $\Phi^{h}$ provide the endogenous variables responses to the shocks, where $h$ represents the horizon of interest. 
The variance decomposition measures the contribution of $e_{i, t}^{\prime}$ shock to the deviations of $y_{i, t+\tau}$ from the baseline forecasted path, where $\tau=1,2, \ldots$. To derive the variance decomposition, we need firstly to calculate the $\tau$-step-ahead forecast error $y_{t+\tau}-\hat{y}_{t+\tau \mid t}$ and the mean square error of the forecast (MSE), $M S E\left(\hat{y}_{t+\tau \mid t}\right)=E\left[\left(y_{t+\tau}-\hat{y}_{t+\tau \mid t}\right)\left(y_{t+\tau}-\hat{y}_{t+\tau \mid t}\right)^{\prime}\right]$. Hence, the percentage change of the variance in $y_{i, t+\tau}$ due to $e_{i, t}^{\prime}$ is the fraction of the variance due to each individual shock divided by the MSE of the $\tau$ forecast period.

Since VARs are reduced-form models, it is impossible to economically interpret the dynamics induced by their disturbances unless theory comes into play. Typically, restrictions employed by the literature included restrictions on the short run or the long run impact of certain shocks on VAR variables or informational delays. Selecting meaningful restrictions is always a difficult task. To disentangle the shocks that might affect the variables of the market $k$, we make some assumptions and impose a particular causal ordering of the endogenous variable using the Cholesky decomposition of matrix $\Sigma$. For examples we assumed that "surprises" in the price level and volatility may be associated with changes in trading volume. Therefore our chosen ordering for VAR variables was to place bond and stock returns first, and place bond and stock transaction costs last, after the markets' volatilities.

One key question that can be addressed with vector autoregression method is how useful some variables are for forecasting the others. If a variable $y_{1, t}$ cannot help forecast another variable $y_{2, t}$, we say that $y_{1, t}$ does not Granger-cause $y_{2, t}$. More formally, $y_{1, t}$ fails to Granger-cause $y_{2, t}$ if for all $s>0$ the mean squared error of a forecast of $y_{1, t+s}$ based on $\left(y_{1, t}, y_{1, t-1}, \ldots\right)$ is the same as the MSE of a forecast of $y_{1, t+s}$ that uses both $\left(y_{1, t}, y_{1, t-1}, \ldots\right)$ and $\left(y_{2, t}, y_{2, t-1}, \ldots\right)$.

We investigate if the stock liquidity shock had any impact for the corporate bond market variables using the block exogeneity version of the Granger causality test. Thus, to test the null hypothesis that the $n_{1}$ variables represented by $y_{1}$ are block-exogenous with respect to the $n_{2}$ variables represented by $y_{2}$, we perform OLS regressions of each of the elements of $y_{1}$ on a constant, $p$ lags of all of the elements of $y_{1}$, and $p$ lags of all of the elements of $y_{2}$, then we calculate the variance-covariance matrix of residuals, $\hat{\Omega}_{11}=\left(\frac{1}{T}\right) \sum_{t=1}^{T}\left[\hat{\varepsilon}_{1, t} \hat{\varepsilon}_{1, t}^{\prime}\right]$. Next we perform OLS regressions of each of the elements of $y_{1}$ on a constant and $p$ lags of all the elements of $y_{1}$, then we calculate the variance-covariance matrix for the residuals obtained from this regression $\hat{\Omega}_{11}(0)=\left(\frac{1}{T}\right) \sum_{t=1}^{T}\left[\hat{\varepsilon}_{1, t}(0) \hat{\varepsilon}_{1, t}^{\prime}(0)\right]$. If

$$
T\left\{\log \left|\hat{\Omega}_{11}(0)\right|-\log \left|\hat{\Omega}_{11}\right|\right\}
$$

is greater than the $5 \%$ critical value for a $\chi^{2}\left(n_{1} n_{2}\right)$ variable, then the null hypothesis is rejected, and the conclusion is that some of the elements of $y_{2}$ are helpful in forecasting $y_{1}$. 


\section{Empirical Results}

\subsection{Descriptive Statistics}

Tables 1 and 2 report the summary statistics for the 900 tickers under our investigation. For variables used from both markets we report the total number of observations, the mean, median, mode, standard deviation, skewness, kurtosis, range and interquartile range in order to capture a detailed picture about the distributions of the variables in the two markets. The sharp difference in the number of observations for the price variable (which also represents the number of trades in the market) between the two markets reflects an important difference for the stock and corporate bond markets which is trading intensity. For the period May 1st-September 30th 2008 the number of observations for the corporate bond market was 772,972 while for the same period, for the stock market, it was $553,251,045$. Only for September 1st-September 30th 2008 period, which is also the period we consider for the VAR investigation, the number of observations for price was 156,280,190 for the stock market while the corresponding number for the corporate bonds was 202,624 . However, with respect to the dollar volume, the average volume of a corporate bond transaction is much higher in comparison to a

stock one. For example, only for September the average dollar volume for the corporate bond market was $\$ 350,535.927$, while for the same period the average dollar volume for the stock market was only $\$ 7,639.771$.

The evolution of the financial turbulence is reflected, also, by the variables' descriptive statistics. For example, the daily average bond price was $\$ 91.3036$ for the May-September period while the mean price only for the September month was $\$ 78.4264$. The average daily yield reflects the same developments with an average daily yield of $\$ 35.7634$ for the May-September period while it raised to $\$ 111.5382$ during the September trading days. On the other hand the stock prices display much less variation over the period. The daily average price was $\$ 27.2190$ for the May-September period and only slightly lower for the September month, at an average of $\$ 25.1968$.

\subsection{Results for Hypotheses Investigation}

The focus of our empirical analysis will be on cross-market effects and causality issues between the stock and corporate bond markets.

Investigating Question No. 1: What are the effects of a liquidity shock in the stock market for the corporate bond market liquidity, returns and volatility?

In order to answer this question, we first estimate the VAR model then we obtain impulse response functions and conduct Granger causality tests. The impulse response functions (IRFs) uncover the 
joint dynamics implied by the VAR system. IRFs trace the impact of a one-time, unit standard deviation shock on the current and future values of the endogenous variables. In order to get meaningful IRFs, innovations are orthogonalized using a Cholesky decomposition of the VAR residuals. ${ }^{24}$ We plot the impulse responses and the $95 \%$ theoretical confidence bands for a period of 20 trading days (steps).

Figure 10 displays the impulse response functions of the endogenous variables to a shock in the stock market liquidity. The impulse responses show that a shock in the stock market liquidity had as result a decrease in the corporate bond market returns and liquidity, and an increase in the corporate bond market volatility. The confidence intervals are tight around the impulse response functions suggesting a good choice of lag length and significant responses.

Table 5 reports Granger-causality tests among the endogenous variables. The tests are reported assuming the same number of lags in VAR for variables from both markets. Based on Akaike information criterion (AIC), we chose a VAR model with one lag length. We found that the stock market liquidity Granger-cause corporate bond volatility and the time-series cross-dependence is significant at $5 \%$ (p-value $=0.0164)$. We, also, found that causality between the stock and corporate bond markets volatilities runs in both directions and is significant at $10 \%$ (p-value $=0.0574$ when causality runs from the stocks volatility toward the corporate bonds volatility, and p-value $=0.0249$ when causality runs from the corporate bonds volatility toward the stocks volatility). Moreover, stock market returns Granger-cause corporate bonds volatility ( $\mathrm{p}$-value $=0.0071$ ), and corporate bond market returns Granger-cause stocks volatility ( $\mathrm{p}$-value $=0.0099$ ).

From investigating the correlation among VAR variables for the September 2008 period (Table 3) we found that cross market correlations were positive and relatively high with the exception of the correlation between stocks volatility and corporate bonds returns which was strong and negative.

Therefore, using data for the September 2008 financial crisis period, our empirical results support partially hypothesis 1 by finding that liquidity decreased in both markets.

Investigating Question No. 2: What are the effects of a liquidity shock in the stock market for the stock and corporate bond markets' resilience? (where market resilience was defined as the speed with

\footnotetext{
${ }^{24}$ For the VAR methodology, we investigated results for two ordering schemes of the variables due to the assumptions we made for identification. Through the ordering we attempt to identify the orthogonal structural shocks, decomposing the shocks to the observables into orthogonal unobserved components. We consequently made just-identified (nontestable) assumptions corresponding to a particular ordering of the endogenous variables in the Cholesky decomposition of matrix $\Sigma$. In the first ordering we placed returns from bonds and stocks firstly, then volatilities in the two markets, and last the corporate bonds and stocks transaction costs. For this ordering, our assumption was that surprises in liquidity may be associated with surprises in returns and volatility. For the second ordering, we placed corporate bonds and stocks transaction costs first then corporate bonds and stocks returns, placing last corporate bonds and stocks volatilities. Our finding was that results from both orderings were qualitatively similar.
} 
which prices recover from a random uninformative shock)

In order to answer this question we need to investigate again the impulse response functions of the endogenous variables to a stock liquidity shock displayed in Figure 10. Figure 10 shows that stock variables recover faster than corporate bond variables after a stock liquidity shock. The corporate bond returns and volatility return to the long run equilibrium after 8 periods versus the corresponding stock variables that return after approximately 6 periods. Therefore, after a stock liquidity shock, the stock market resilience is higher than the corporate bond market resilience, and our empirical results confirm hypothesis 2 .

Investigating Question No. 3: How long does it take for the new information regarding the short sell ban in the stock market to be impounded into the corporate bonds prices? Figures 5 through 10 which display the IRFs give us the possibility to answer this question. The empirical impulse response functions are consistent with the theoretical simulations reported by Holden and Subrahmanyam (1992). Their model theoretical prediction is that the speed with which variables decline to 0 after an initial shock should increase with the trading frequency. Summary statistics for the two markets showed that trading frequency is incomparable much lower for the corporate bond market versus the stock market. Hence, our obtained empirical IRFs, showing a faster convergence to the long run equilibrium for stock variables versus the bond variables after an initial perturbation, confirm Holden and Subrahmanyam (1992) theoretical findings and the empirical evidence from stock market found by Manganelli (2005).

Investigating Question No. 4: Do pessimist investors switch from the stock market into the corporate bond market after imposing a short sell ban in the stock market? In order to answer this question we analyze plots of volumes, prices and spreads from figure 1 and 2 , and plots of returns and volatilities from figure 3 and 4 for the two considered markets. The graphs for corporate bonds volume and volatility for the period May 1st-September 30th and September 1st-September 30th confirm our fourth hypothesis. After the ban we observe an increase in corporate bond volume and volatility. 


\section{Conclusion}

This empirical study exploits the natural experiment from September 2008 that is the U.S. Securities and Exchange Commission Emergency Order prohibiting stocks short sales for 900 financial firms. We investigated the impacts such a measure had for the corporate bond market during the September 2008 period. We report evidence that short sale restrictions in the stock market had a negative impact on corporate bond market quality. This evidence supports an integrated market view from the regulatory side, suggesting that future regulatory measures should consider simultaneous actions in both markets. 


\section{References}

Abrew, D., Brunnermeier, M.K., (2002): Synchronization risk and delayed arbitrage, Journal of Financial Economics, 66, 341-360.

Admati, Anat R., Pfleiderer, Paul (1988): A Theory of Intraday Patterns: Volume and Price Variability, The Review of Financial Studies 1988, Volume 1, number 1, pp. 3-40

Ali, Ashiq, Trombley, Mark A. (2006): Short Sales Constraints and Momentum in Stock Returns, Journal of Business, Finance and Accounting, 33(3)\&4, 587-615, April/May 2006

Amihud, Yakov, Mendelson, Haim (1986): Asset pricing and the bid-ask spread, Journal of Financial Economics, 17, 223-249

Andersen, Jorgen Vitting (2005): Could short selling make financial markets tumble?, International Journal of Theoretical and Applied Finance

Asquith, Paul, Oman, Rebecca, Safaya, Christopher: Short Sales and Trade Classification Algorithms, NBER Working Paper No. 14158, Issued in July 2008

Asquith, Paul, Pathak, Parag A., Ritter, Jay R. (2005): Short Interest, Institutional Ownership, and Stock Returns, Journal of Financial Economics 78(2005) 243-276

Au, Andrea S., Doukas, John A., Onayev, Zhan (2007): Daily Short Interest, Idiosyncratic Risk, and Stock Returns,

Bagehot, Walter (1971): The only game in town, Financial Analyst Journal, 27, 12-14

Berkowitz, Jeremy, Kumar, Praveen, Langberg, Nisan: Price Discovery and Dynamic Information Revelation in the Financial Crisis of 2008, University of Houston, Department of Finance working paper

Bessembinder, Hendrik, Maxwell, William, Venkataraman, Kumar (2006): Market transparency, liquidity externalities, and institutional trading costs in corporate bonds, Journal of Financial Economics 82 (2006) 251-288

Bessembinder, Hendrik, Maxwell, William, Venkataraman, Kumar: Optimal Market Transparency: Evidence from the Initiation of Trade Reporting in Corporate Bonds, Working paper version 
Boehmer, Ekkehart, Jones, Charles M., Zhang, Xiaoyan (2008): Which Shorts are Informed?, The Journal of Finance, Volume 63, Number 2, April 2008 , pp. 491-527(37)

Boehmer, Ekkehart, Jones, Charles M., Zhang, Xiaoyan (2008): Unshackling Short Sellers: The Repeal of the Uptick Rule, Working paper, Columbia Business School, December 2008

Bris, Arturo, Goetzmann, William N., Zhu, Ning (2004): Efficiency and the Bear: Short Sales and Markets around the World, Journal of Finance, forthcoming

Brunnermeier, Markus K., Pedersen, Lasse Heje (2008): Market Liquidity and Funding Liquidity,

Chang, Eric C., Yu Yinghui (2007): Short-Sales Constraints and Price Discovery: Evidence from the Hong Kong Market, The Journal of Finance, Volume 62, Issue 5, pages 2097-2121

Charoenrook, Anchada, Daouk, Hazem (2005) : A Study of Market-Wide Short-Selling Restrictions

Chen, Honghui, Singal, Vijay (2003): Role of Speculative Short Sales in Price Formation: Case of the Weekend Effect, Journal of Finance 58, April 2003, 685-705

Chordia, Tarun, Roll, Richard, Subrahmanyam , Avanidhar (2000): Commonality in liquidity, Journal of Financial Economics 56, 3-28

Chordia, Tarun, Sarkar Asani, Subrahmanyam, Avanidhar (2005): An Empirical Analysis of Stock and Bond Market Liquidity, Review of Financial Studies, 18, 85-129

Christophe, Stephen E., Ferri, Michael G., Angel, James J. (2004): Short-Selling Prior to Earnings Announcements, Journal of Finance, 59, 1845-1875

Danielsen, Bartley R., Sorescu, Sorin M. (2001): Why Do Option Introductions Depress Stock Prices? A Study of Diminishing Short-Sale Constraints, Journal of Financial and Quantitative Analysis, pp. $451-484$

Daske, Holger, Richardson, Scott A., Tuna, Irem (2005): Do short sale transactions precede bad news events?, The Wharton School, University of Pennsylvania

Demsetz, Harold (1968): The Cost of Transacting, The Quarterly Journal of Economics, Vol.82, No.1 (Feb. 1968), pp 33-53

Diamond, D., Verrechia, R.(1987): Constraints on short-selling and asset price adjustment to private information., Journal of Financial Economics, 18, 277-311. 
Diether, Karl B., Lee, Kuan-Hui, Werner, Ingrid M. (2007): Short-Sale Strategies and Return Predictability, Working paper, The Ohio State University

Edwards, Amy K., Harris, Lawrence E., Piwowar, Michael S. (2007): Corporate Bond Market Transaction Costs and Transparency, The Journal of Finance, Volume 62 Issue 3, pp. 1421 - 1451, 8 May 2007

Easley, David, O’Hara, Maureen (1987): Price, Trade Size, and Information in Securities Markets, Journal of Financial Economics, 19 (1987), 69-90

Easley, David, O'Hara, Maureen (1992): Time and the Process of Security Price Adjustment, The Journal of Finance, Vol. XLVII, No.2, June 1992

Ederington, Louis H, Lee, Jae Ha (1993): How markets process information: news releases and volatility, Journal of Finance, September 48(4), 1161-1191

Foster, Douglas, F., and Viswanathan, S. (1994): Strategic Trading with Asymmetrically Informed Traders and Long-Lived Information, Journal of Finance and Quantitative Analysis, 1994 , 29, $499-518$

Goyenko, Ruslan, Ukhov, Andrey (2009): Stock and Bond Market Liquidity: A Long-Run Empirical Analysis, Journal of Financial and Quantitative Analysis, 44 (2009), 189-212

Goyenko, Ruslan, Subrahmanyam, Avanidhar, Ukhov, Andrey: The Term Structure of Bond Market Liquidity, Journal of Financial and Quantitative Analysis, forthcoming

Graham, Edward J., Hughen, Christopher (2007): Ownership Structure, Expectations, and Short Sales on the NASDAQ, Journal of Economics and Finance, Volume 31, Number 1

Hamilton, James D. (1994): Time Series Analysis, Princeton University Press

Harris, Lawrence E., Piwowar, Michael S. (2006): Secondary Trading Costs in the Municipal Bond Market, The Journal of Finance, Vol. LXI, No. 3, June 2006

Hasbrouck, Joel (1995): One Security, Many Markets: Determining the Contributions to Price Discovery, The Journal of Finance, Vol. L, No. 4, September 1995

Henker, Thomas, Wang, Jian-Xin (2006): On the importance of timing specifications in market microstructure research, Journal of Financial Markets, 9 (2006), 162-179 
Hong, Harrison, Stein, Jeremy C. (2003): Differences of Opinion, Short-Sales Constraints, and Market Crashes, The Review of Financial Studies, Summer 2003, Vol. 16, No. 2, pp. 487-525

Holden, Craig W. (1995): Index Arbitrage as Cross-Sectional Market Making, The Journal of Futures Markets, Vol. 15, No. 4, 423-455 (1995)

Holden, Craig W., Subrahmanyam, Avanidhar (1992): Long-lived private information and imperfect competition, Journal of Finance 47, 247-270

Huang, Roger D., Stoll, Hans R. (1997): The Components of the Bid-Ask Spread: A General Approach, The Review of Financial Studies, Winter 1997, Vol. 10, No. 4, pp. 995-1034

Jotikasthira, Chotibhak (2007): Does Search Friction Really Matter? Evidence from the Corporate Bond Market, Working paper, Kelley School of Business, Indiana University

Kadapakkam, Palani-Rajan, Shi, Yilun (2007): The Effect of Short-Selling Constraints on Earning Announcements: the Case of Hong Kong ,

Karpoff, Jonathan M., Lou, Xiaoxia (2008): Do Short Sellers Detect Overpriced Firms? Evidence from SEC Enforcement Actions, Working paper, University of Washington

Kumar, Praveen, Seppi, Duane J (1994): Information and index arbitrage, Journal of Business, 1994, vol.67, nr. 4

Lamont, O. A., (2004): Go down fighting: Short sellers vs. firms., NBER working paper n. 10659

Lee, Charles M. C., Ready, Mark J. (1991): Inferring Trade Direction from Intraday Data, The Journal of Finance, Vol. XLVI, No. 2, June 1991

Manganelli, Simone (2005): Duration, volume and volatility impact of trades, Journal of Financial Markets 8 (2005) 377-399

Merton, Robert C. (1974): On the pricing of corporate debt: An empirical study, Journal of Finance, $29,449-470$

Nigmatullin, Eldar, Tyurin, Konstantin, Yin, Hao (2007): Heterogeneous VAR Dynamics of Limit Order Book Depth, Trade Imbalance, and Volatility of the NYSE, Indiana University Working Paper 
Miller, Edward M. (1997): Risk, Uncertainty, and Divergence of Opinion, The Journal of Finance, Vol XXXII, No. 4, September 1977

O'Hara, Maureen: Market Microstructure Theory, Blackwell Publishing 2007

O'Hara, Maureen, Oldfield, George S. (1986): The microeconomics of market making, Journal of Financial and Quantitative Analsyis, 21, 361-376

Reed, Adam V. (2007): Costly Short Selling and Stock Price Adjustment to Earnings Announcements,

Shkilko, Andriy, Van Ness, Bonnie, Van Ness, Robert (2007): Predatory Short Selling

Subrahmanyam, Avanidhar (1991): A Theory of Trading in Stock Index Futures, The Review of Financial Studies 1991, Volume 4, number 1, pp. 17-51

Thomas, Stephen H. (2006): Short Selling: Discussion of Short Sales Constraints and Momentum in Stock Returns, University of Southampton, March 2006, Number CRR-06-01, ISSN 1356-3548

Zhao, Min (2007): The Tick-Test Rule, Investors' Opinions Dispersion, and Stock Returns: The Daily Evidence, Working Paper, Finance Department, University of Tennessee, October 2007

Xu, Yexiao, Zhang, Harold H., Zhou, Xin: Understanding the Information Content of Short Interests, 

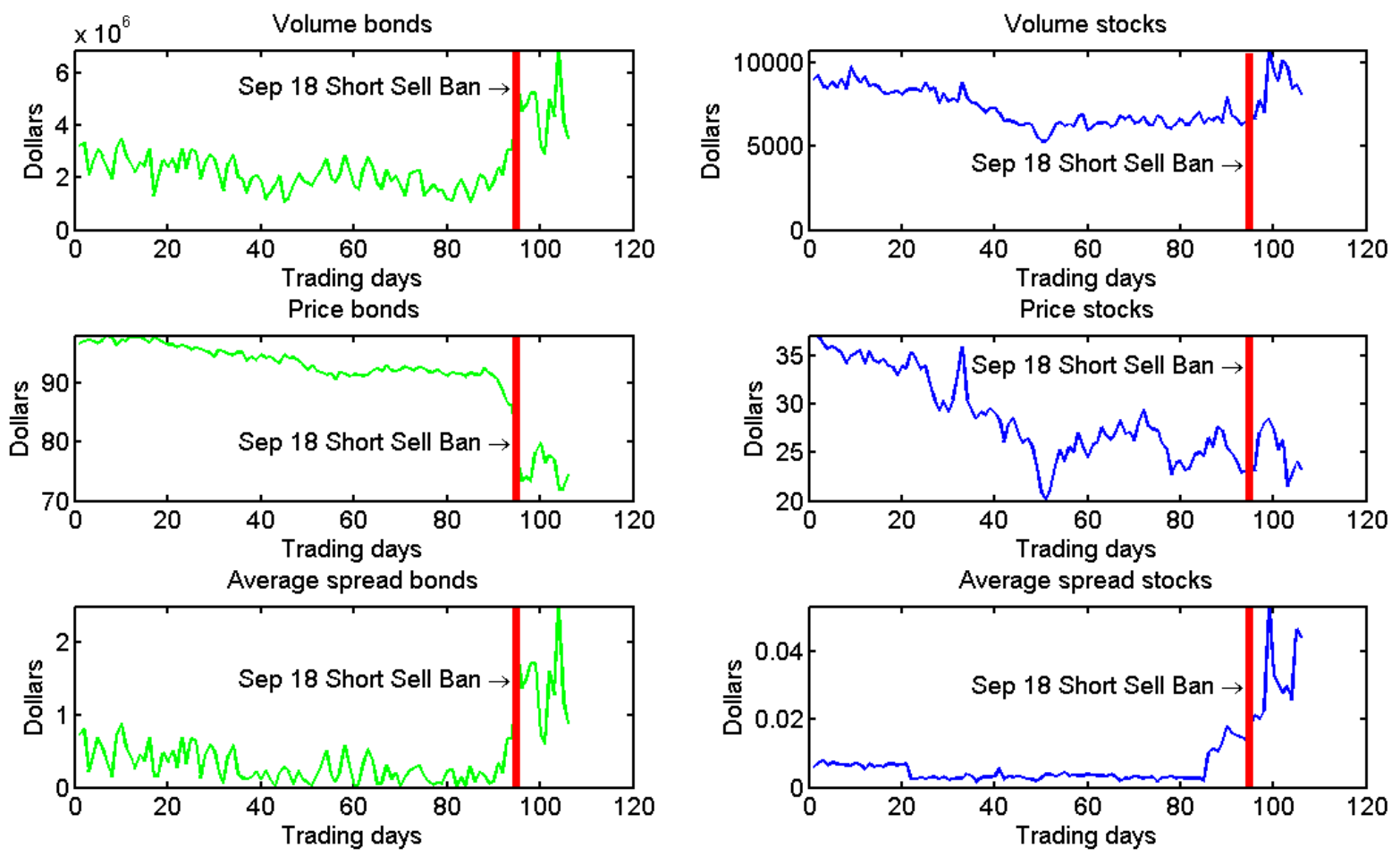

Figure 1: Figure displays plots of daily volume, price and spread for stocks and corporate bonds belonging to the 900 financial firms that were subject to the September 2008 short sell ban. The daily equally-weighted average is computed first for each security and then the cross-sectional average is obtained for each trading day in each market. The data cover the period from May 1st 2008 till September 30th 2008. 

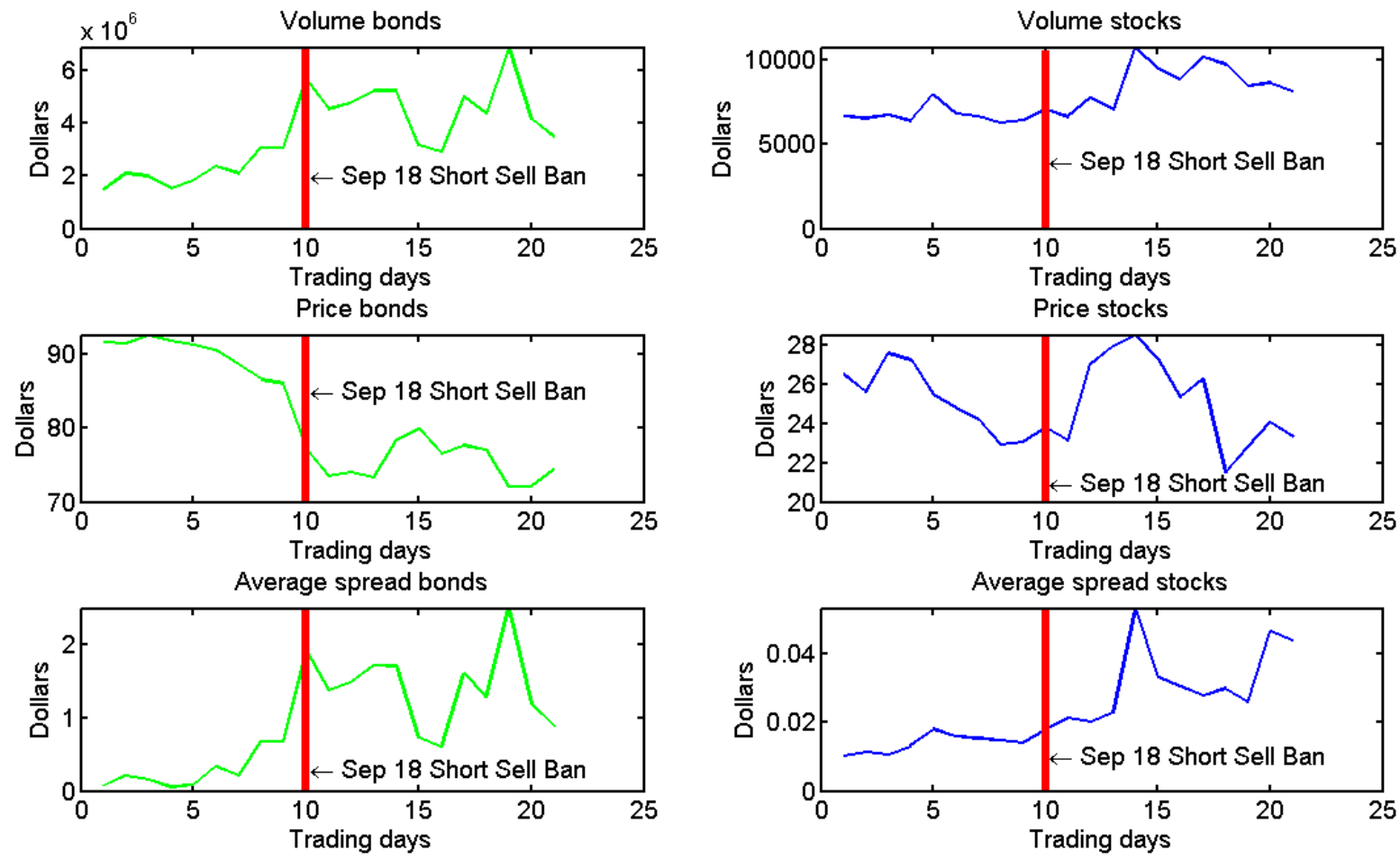

Figure 2: Figure displays plots of daily volume, price and spread for stocks and corporate bonds belonging to the 900 financial firms that were subject to the September 2008 short sell ban. The daily equally-weighted average is computed first for each security and then the cross-sectional average is obtained for each trading day in each market. The data cover the period from September 1st 2008 till September 30th 2008. 

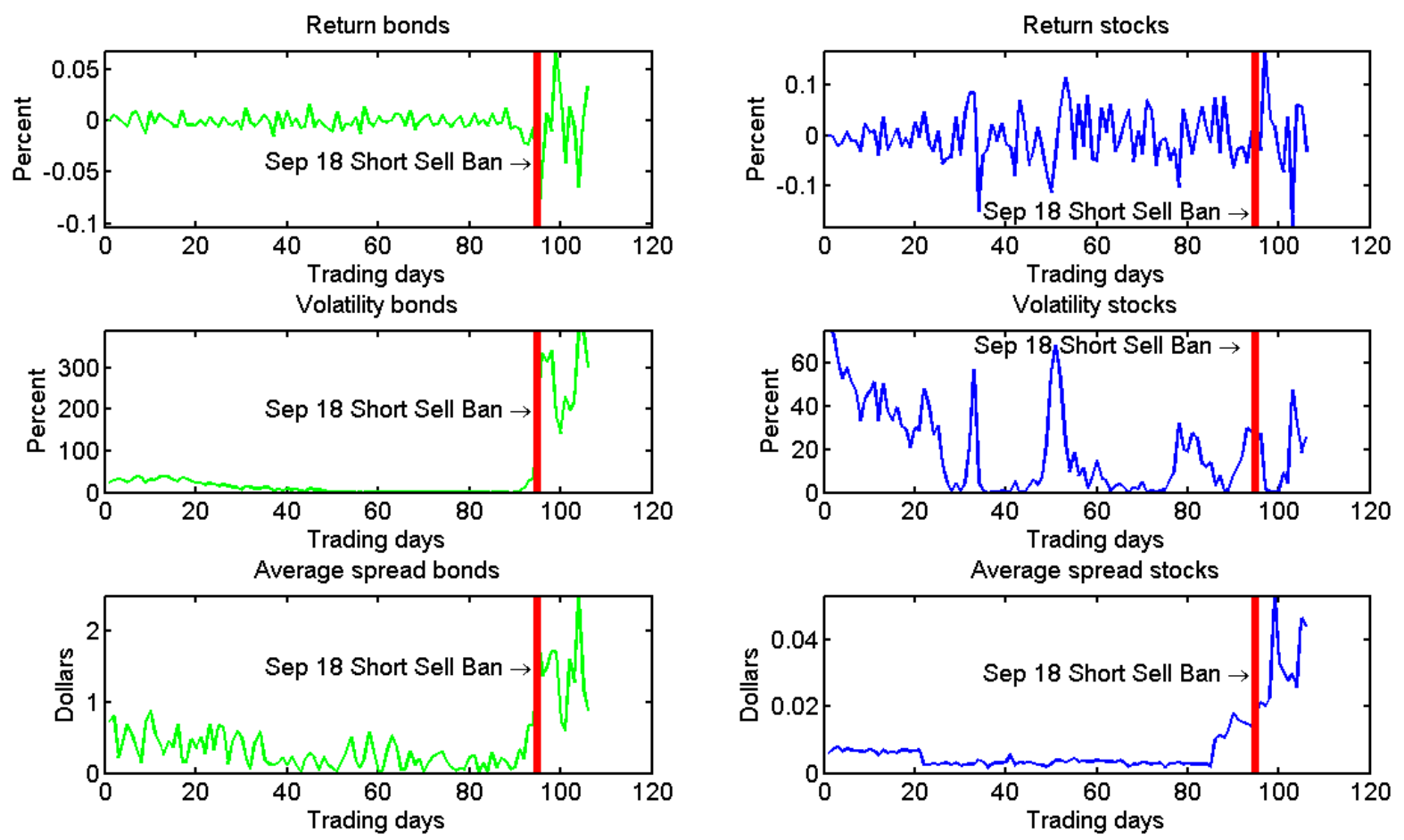

Figure 3: Figure displays plots of daily returns, volatility and spread for stocks and corporate bonds belonging to the 900 financial firms that were subject to the September 2008 short sell ban. The daily equally-weighted average is computed first for each security and then the cross-sectional average is obtained for each trading day in each market. The data cover the period from May 1st 2008 till September 30th 2008. 

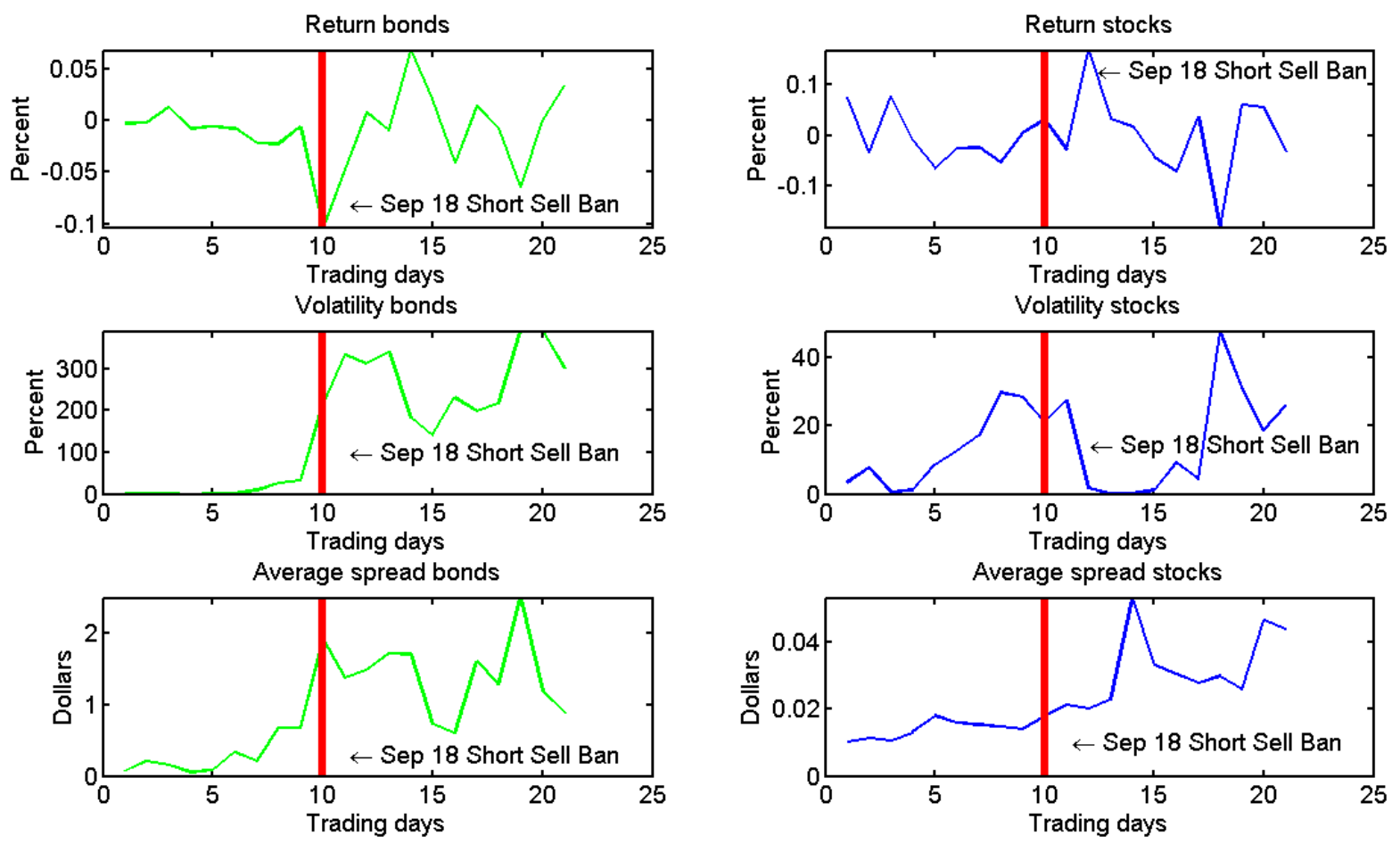

Figure 4: Figure displays plots of daily returns, volatility and spread for stocks and corporate bonds belonging to the 900 financial firms that were subject to the September 2008 short sell ban. The daily equally-weighted average is computed first for each security and then the cross-sectional average is obtained for each trading day in each market. The data cover the period from September 1st 2008 till September 30th 2008. These variable are the ones that are analyzed using VAR. 

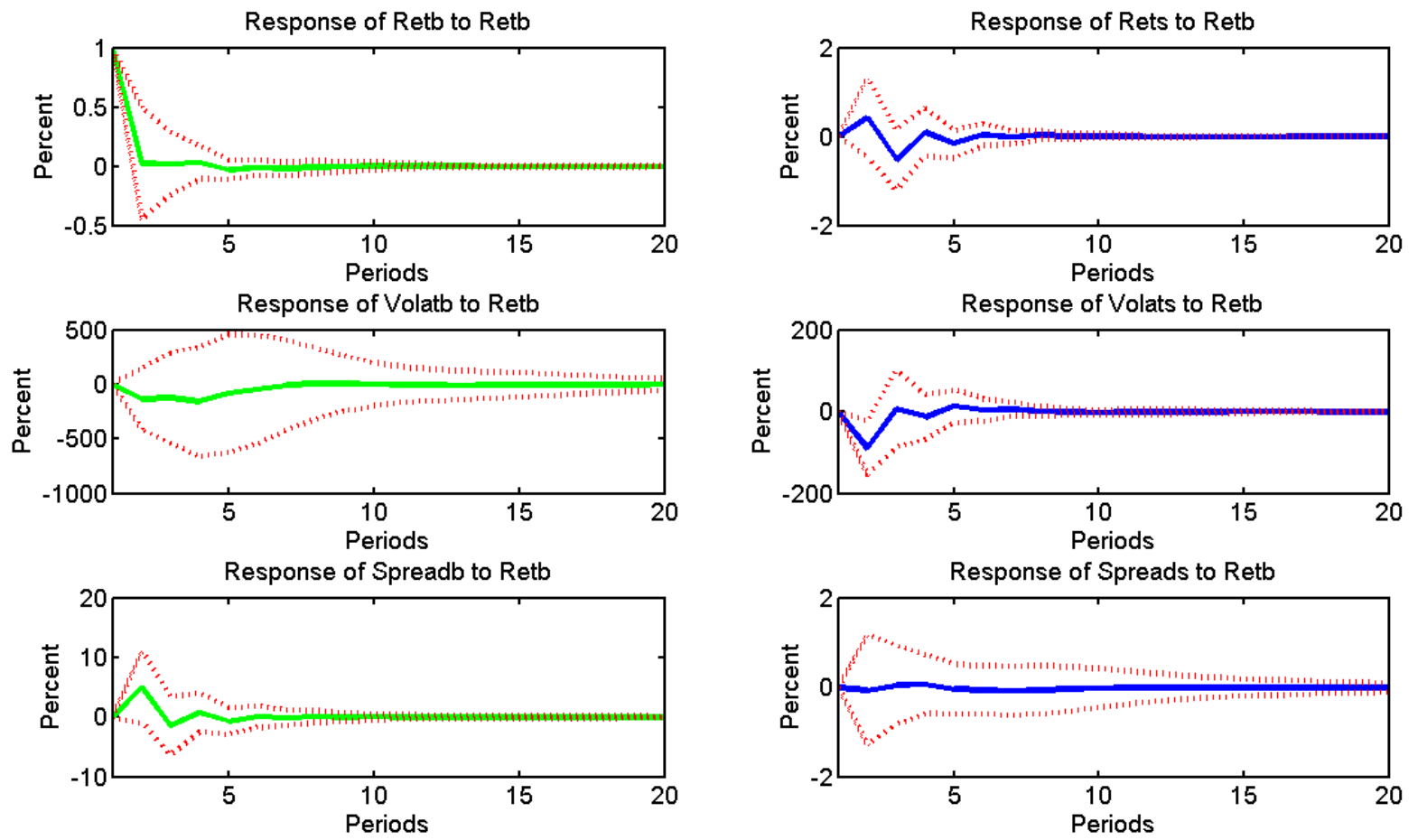

Figure 5: Impulse response functions of endogenous variables to a shock in corporate bonds returns. The upper, middle and lower lines are, respectively, the 95th, 50th, and 5th percentile based on the sample of estimated response functions for stocks and corporate bonds belonging to the 900 financial firms that were subject to the September 2008 short sell ban. The data cover the period from September 1st 2008 till September 30th 2008. As notation the following mapping is valid: Retb are the corporate bonds returns, Rets are the stocks returns, Volatb is the corporate bonds volatility, Volats is the stocks volatility, Spreadb are the corporate bonds transaction costs, and Spreads are the stocks transaction costs. 

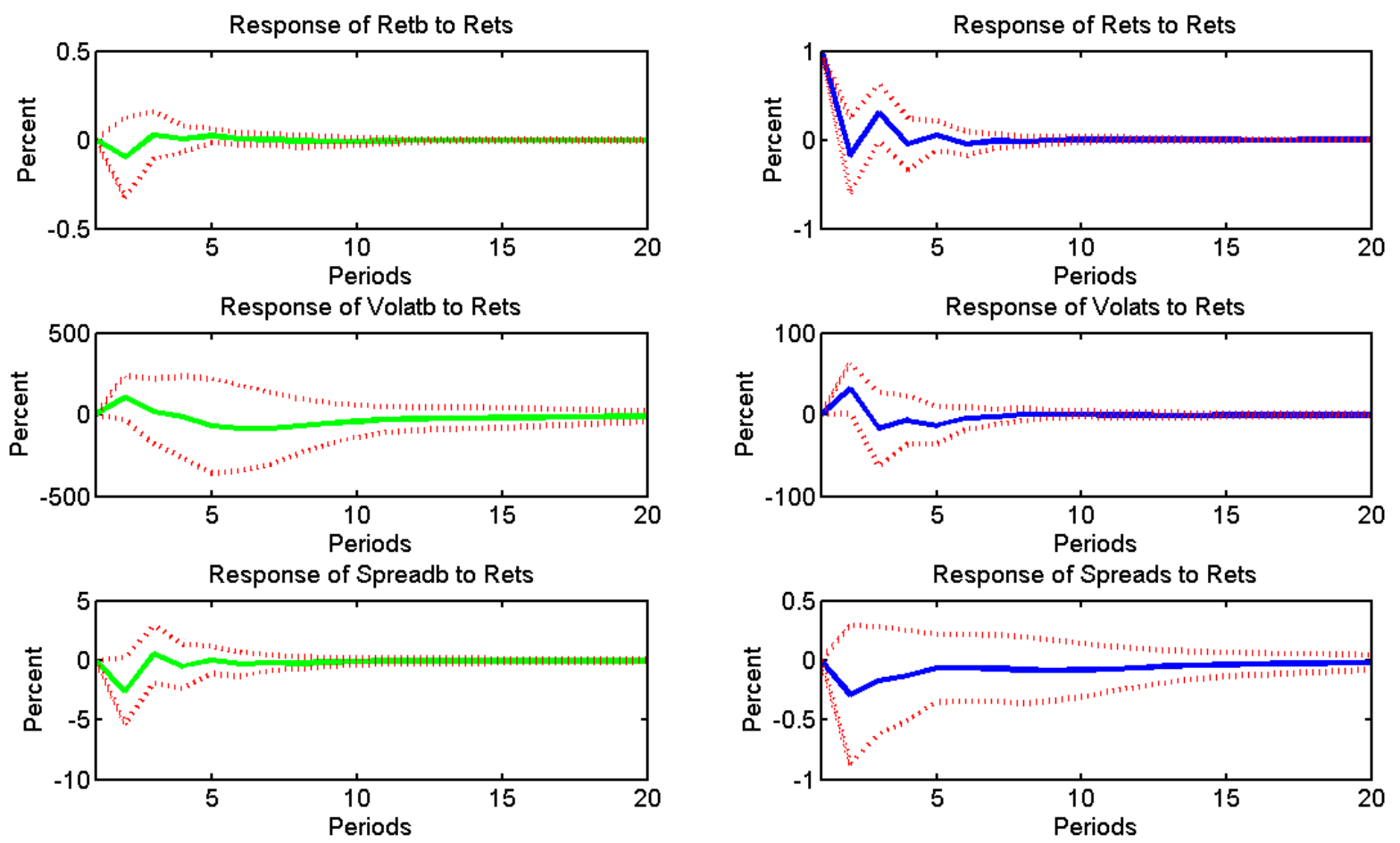

Figure 6: Impulse response functions of endogenous variables to a shock in stocks returns. The upper, middle and lower lines are, respectively, the 95th, 50th, and 5th percentile based on the sample of estimated response functions for stocks and corporate bonds belonging to the 900 financial firms that were subject to the September 2008 short sell ban. The data cover the period from September 1st 2008 till September 30th 2008. As notation the following mapping is valid: Retb are the corporate bonds returns, Rets are the stocks returns, Volatb is the corporate bonds volatility, Volats is the stocks volatility, Spreadb are the corporate bonds transaction costs, and Spreads are the stocks transaction costs. 

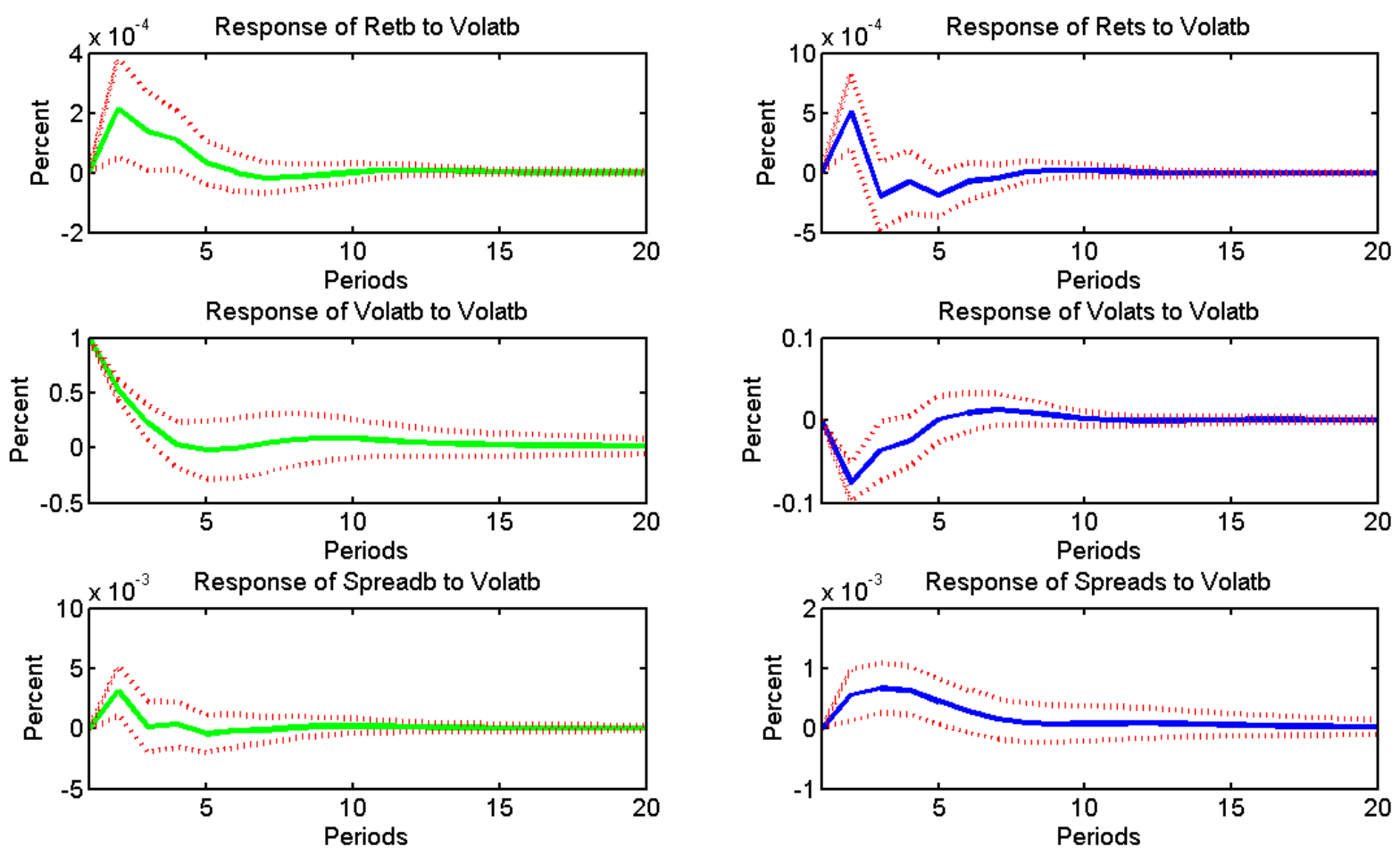

Figure 7: Impulse response functions of endogenous variables to a shock in corporate bonds volatility. The upper, middle and lower lines are, respectively, the 95th, 50th, and 5th percentile based on the sample of estimated response functions for stocks and corporate bonds belonging to the 900 financial firms that were subject to the September 2008 short sell ban. The data cover the period from September 1st 2008 till September 30th 2008. As notation the following mapping is valid: Retb are the corporate bonds returns, Rets are the stocks returns, Volatb is the corporate bonds volatility, Volats is the stocks volatility, Spreadb are the corporate bonds transaction costs, and Spreads are the stocks transaction costs. 

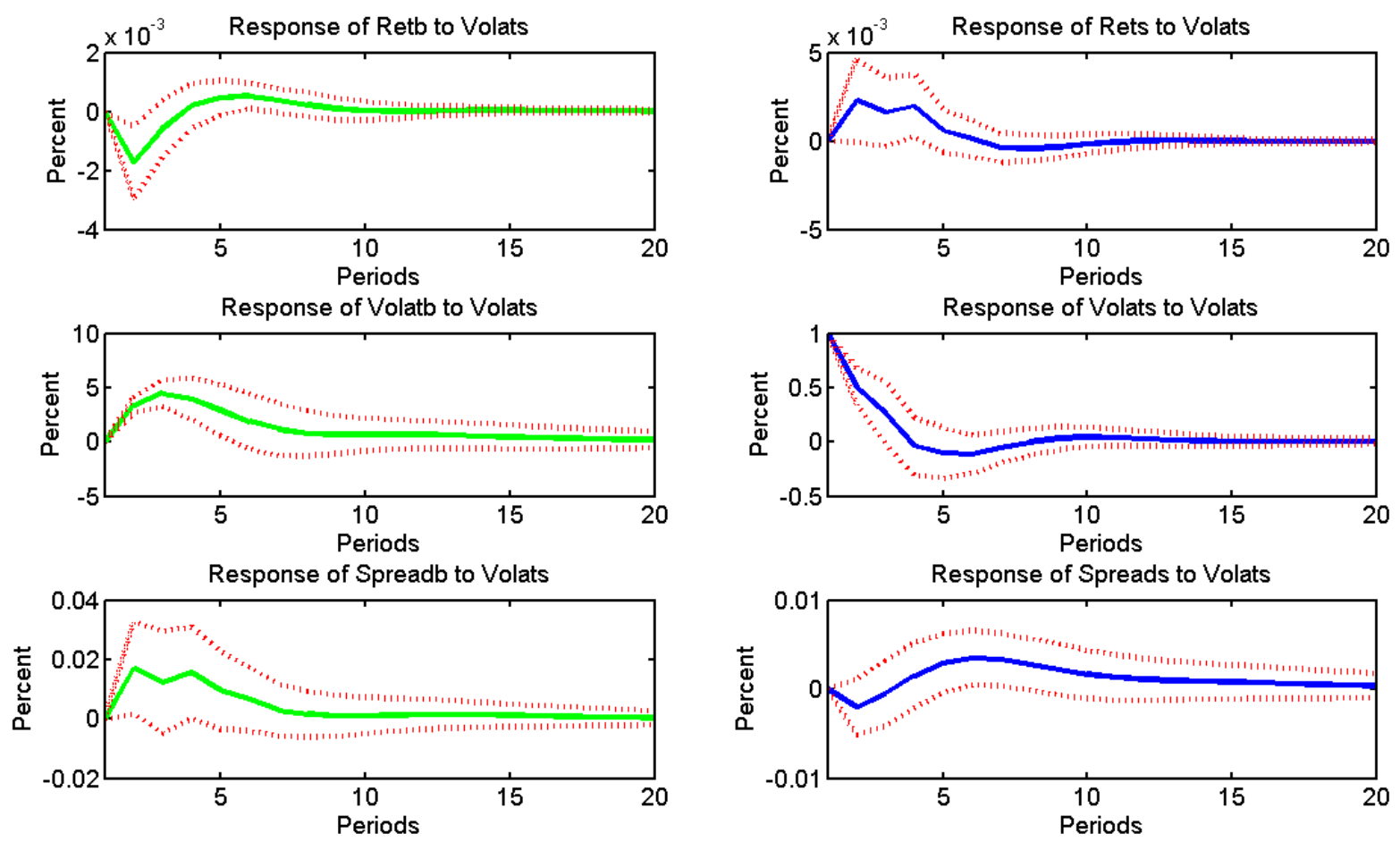

Figure 8: Impulse response functions of endogenous variables to a shock in stocks volatility. The upper, middle and lower lines are, respectively, the 95th, 50th, and 5th percentile based on the sample of estimated response functions for stocks and corporate bonds belonging to the 900 financial firms that were subject to the September 2008 short sell ban. The data cover the period from September 1st 2008 till September 30th 2008. As notation the following mapping is valid: Retb are the corporate bonds returns, Rets are the stocks returns, Volatb is the corporate bonds volatility, Volats is the stocks volatility, Spreadb are the corporate bonds transaction costs, and Spreads are the stocks transaction costs. 

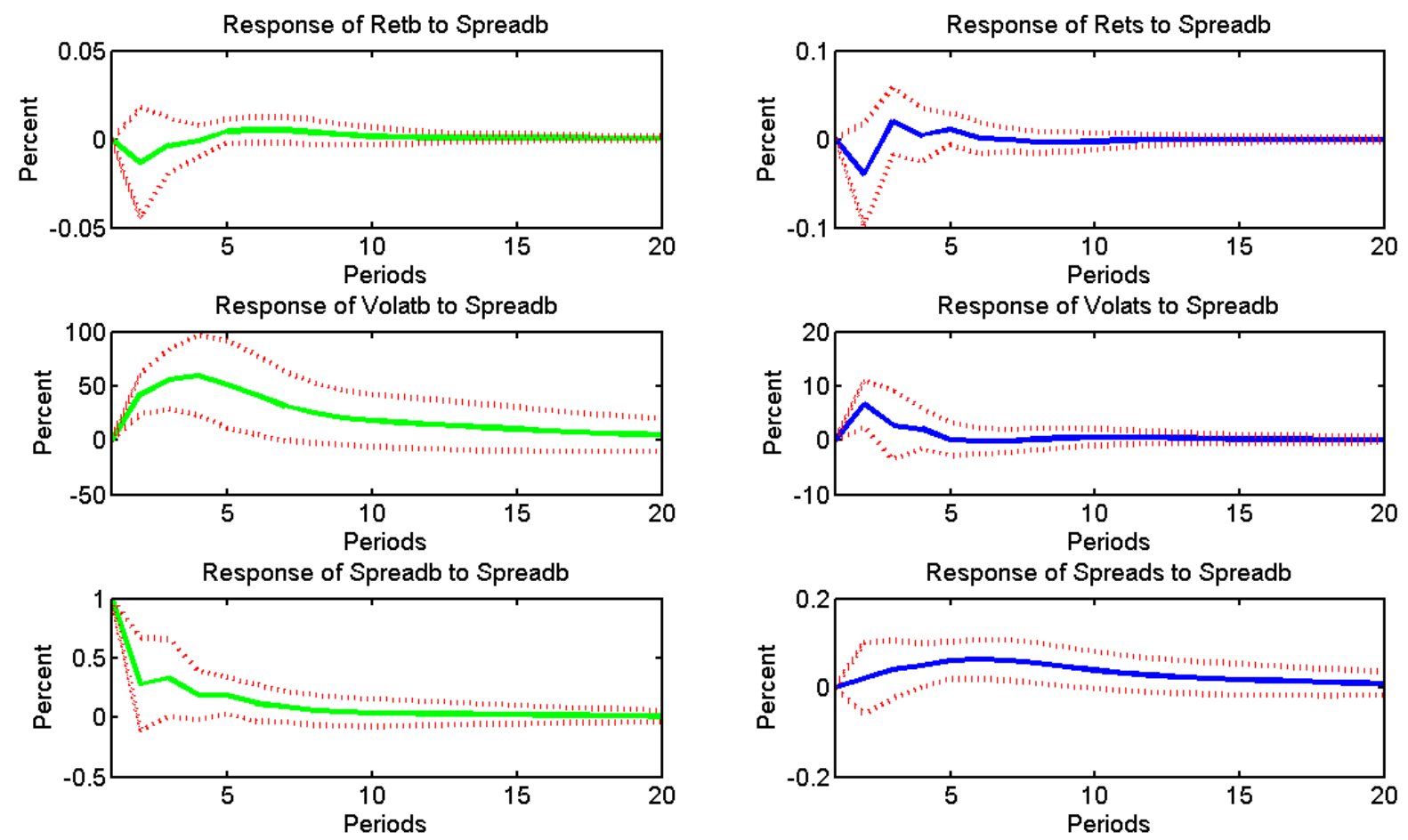

Figure 9: Impulse response functions of endogenous variables to a shock in corporate bonds transaction costs. The upper, middle and lower lines are, respectively, the 95th, 50th, and 5th percentile based on the sample of estimated response functions for stocks and corporate bonds belonging to the 900 financial firms that were subject to the September 2008 short sell ban. The data cover the period from September 1st 2008 till September 30th 2008. As notation the following mapping is valid: Retb are the corporate bonds returns, Rets are the stocks returns, Volatb is the corporate bonds volatility, Volats is the stocks volatility, Spreadb are the corporate bonds transaction costs, and Spreads are the stocks transaction costs. 

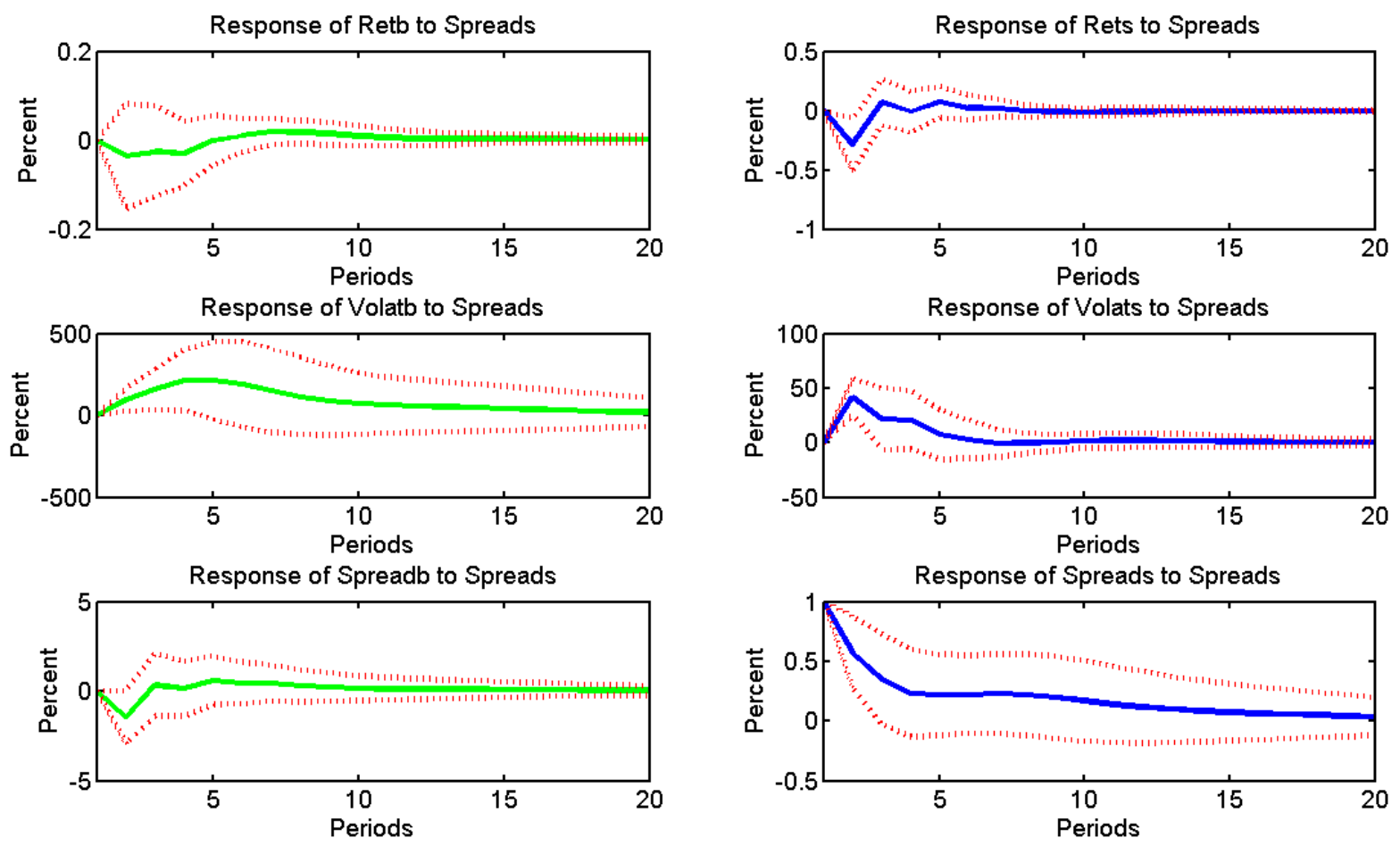

Figure 10: Impulse response functions of endogenous variables to a shock in stocks transaction costs. The upper, middle and lower lines are, respectively, the 95th, 50th, and 5th percentile based on the sample of estimated response functions for stocks and corporate bonds belonging to the 900 financial firms that were subject to the September 2008 short sell ban. The data cover the period from September 1st 2008 till September 30th 2008. As notation the following mapping is valid: Retb are the corporate bonds returns, Rets are the stocks returns, Volatb is the corporate bonds volatility, Volats is the stocks volatility, Spreadb are the corporate bonds transaction costs, and Spreads are the stocks transaction costs. 
Table 1: This table provides corporate bonds descriptive statistics for the sample of 900 financial firms for which stocks short sell ban was imposed on September 18th 2008. The table gives information about the distributions of corporate bond transaction variables: corporate bond price, trading volume and yield, as obtained from the TRACE engine. The period for which we extracted the data set is May 1st-September 30th 2008.

\begin{tabular}{|c|c|c|}
\hline & September & May-September \\
\hline \hline Price & & \\
\hline \hline Total Number & 202,624 & 772,972 \\
Mean & 78.4264904 & 91.3036249 \\
Median & 89.2100 & 97.0000 \\
Mode & 100.0000 & 100.0000 \\
Standard Deviation & 38.612514 & 23.31438 \\
Skewness & 96.1441491 & 113.603736 \\
Kurtosis & $19,885.7004$ & $38,977.876$ \\
Range & 9,250 & 9,250 \\
Interquartile Range & 28.12500 & 9.43500 \\
\hline \hline Dollar Volume & & \\
\hline \hline Total Number & 202,623 & 772,969 \\
Mean & $350,535.927$ & $305,998.701$ \\
Median & $25,000.0$ & $25,000.0$ \\
Mode & $10,000.0$ & $10,000.0$ \\
Standard Deviation & $1,002,460.57$ & 952,972 \\
Skewness & 3.82959508 & 4.11315385 \\
Kurtosis & 14.142188 & 16.4244407 \\
Range & $4,999,500$ & $4,999,500$ \\
Interquartile Range & 90,000 & 56,000 \\
\hline \hline Yield & & \\
\hline \hline Total Number & 184,061 & 707,534 \\
Mean & 111.5382 & 35.7634744 \\
Median & 9.2280 & 6.50700 \\
Mode & 8.7670 & 7.00000 \\
Standard Deviation & $4,023.76803$ & 2,149 \\
Skewness & 124.074101 & 227.228133 \\
Kurtosis & $20,025.2513$ & $66,738.2352$ \\
Range & 852,899 & 852,899 \\
Interquartile Range & 14.73376 & 2.72534 \\
\hline
\end{tabular}


Table 2: This table provides stocks descriptive statistics for the sample of 900 financial firms for which short sell ban was imposed on September 18th 2008. The table gives information about the distributions of stocks variables: price and number of shares traded, as obtained from the TAQ trades data. The period for which we extracted the data set is May 1st-September 30th 2008.

\begin{tabular}{|c|c|c|}
\hline & September & May-September \\
\hline \hline Price & & \\
\hline \hline Total Number & $156,280,190$ & $553,251,045$ \\
Mean & 25.1968419 & 27.21909 \\
Median & 19.33000 & 22.00000 \\
Mode & 20.00000 & 5.00000 \\
Standard Deviation & 29.20240 & 33.95503 \\
Skewness & 880.695812 & 991.088022 \\
Kurtosis & $4,511,679.09$ & $3,142,111.22$ \\
Range & 150,500 & 150,500 \\
Interquartile Range & 24.82000 & 22.12000 \\
\hline \hline Size (Number of Shares) & & \\
\hline \hline Total Number & $156,280,190$ & $553,251,045$ \\
Mean & 303.203521 & 265.918862 \\
Median & 100.0000 & 100.0000 \\
Mode & 100.0000 & 100.0000 \\
Standard Deviation & 5,212 & 3,715 \\
Skewness & $2,660.20165$ & $2,497.00621$ \\
Kurtosis & $14,054,610.3$ & $16,260,550.5$ \\
Range & $34,648,999$ & $34,648,999$ \\
Interquartile Range & 100.00000 & 100.00000 \\
\hline
\end{tabular}

Table 3: This table displays the correlation matrix for VAR variables. The data used to calculate correlations in this table cover the period from September 1st 2008 till September 30th 2008. As notation we denote by Ret to mean returns and Volat to mean volatility.

\begin{tabular}{|c|c|c|c|c|c|c|}
\hline & Ret bonds & Ret stocks & Volat bonds & Volat stocks & Spread bonds & Spread stocks \\
\hline Ret bonds & 1 & & & & & \\
Ret stocks & 0.0486 & 1 & & & & \\
Volat bonds & -0.1679 & 0.2185 & 1 & & & \\
Volat stocks & -0.4131 & -0.4937 & 0.2459 & 1 & & \\
Spread bonds & -0.2522 & 0.2621 & 0.8206 & 0.2714 & 1 & 1 \\
Spread stocks & 0.4229 & -0.0893 & 0.6180 & 0.0694 & 0.4694 & 1 \\
\hline
\end{tabular}


Table 4: This table displays the correlation matrix for VAR variables. The data used to calculate correlations in this table cover the period from May 1st 2008 till September 30th 2008. As notation we denote by Ret to mean returns and Volat to mean volatility.

\begin{tabular}{|c|c|c|c|c|c|c|}
\hline & Ret bonds & Ret stocks & Volat bonds & Volat stocks & Spread bonds & Spread stocks \\
\hline Ret bonds & 1 & & & & & \\
Ret stocks & -0.0241 & 1 & & & & \\
Volat bonds & -0.2465 & 0.1057 & 1 & & & \\
Volat stocks & -0.0842 & -0.0879 & 0.0471 & 1 & & \\
Spread bonds & -0.2745 & 0.1429 & 0.8283 & 0.1532 & 1 & 1 \\
Spread stocks & 0.0497 & -0.0087 & 0.8141 & 0.0060 & 0.6767 & 1 \\
\hline
\end{tabular}

Table 5: This table presents Granger Causality Tests (Chi-square statistics and p-values) based on the VAR estimated for the sample of 900 financial firms for which short sell ban was imposed on September 18th 2008. VAR is estimated with one lag. The data cover the period from September 1st 2008 till September 30th 2008. The null hypothesis is that the lagged values of the variables in the columns 2-7 do not improve VAR predictions of the variables in the first column. As notation we denote by Ret to mean returns and Volat to mean volatility.

\begin{tabular}{|c|c|c|c|c|c|c|}
\hline & Ret bonds & Ret stocks & Volat bonds & Volat stocks & Spread bonds & Spread stocks \\
\hline Ret bonds & 0.0063 & 0.7785 & 0.0203 & 0.5217 & 2.5533 & 0.1521 \\
& $(0.9368)$ & $(0.3776)$ & $(0.8868)$ & $(0.4701)$ & $(0.1101)$ & $(0.6966)$ \\
Ret stocks & 0.5059 & 0.6284 & 0.0168 & 0.3339 & 2.7236 & 0.9867 \\
& $(0.4769)$ & $(0.4279)$ & $(0.8968)$ & $(0.5634)$ & $(0.0989)$ & $(0.3205)$ \\
Volat bonds & 4.9904 & 7.2477 & 7.7957 & 3.6099 & 5.7808 & 5.7561 \\
& $(0.0255)$ & $(0.0071)$ & $(0.0052)$ & $(0.0574)$ & $(0.0162)$ & $(0.0164)$ \\
Volat stocks & 6.6450 & 2.5229 & 5.0283 & 3.8902 & 2.0731 & 2.2238 \\
& $(0.0099)$ & $(0.1122)$ & $(0.0249)$ & $(0.0486)$ & $(0.1499)$ & $(0.1359)$ \\
Spread bonds & 0.8384 & 1.5858 & 1.7703 & 1.1497 & 1.5474 & 1.4936 \\
& $(0.3599)$ & $(0.2079)$ & $(0.1833)$ & $(0.2836)$ & $(0.2135)$ & $(0.2217)$ \\
Spread stocks & 0.0586 & 4.0738 & 0.0006 & 1.4393 & 3.3728 & 0.3871 \\
& $(0.8087)$ & $(0.0436)$ & $(0.9806)$ & $(0.2303)$ & $(0.0663)$ & $(0.5338)$ \\
\hline
\end{tabular}


Table 6: This table shows forecast error variance decomposition obtained for the variables in the VAR estimated for the sample of 900 financial firms for which short sell ban was imposed on September 18th 2008. VAR is estimated with one lag. The data cover the period from September 1st 2008 till September 30th 2008. Entry $(i, j)$ of each panel shows the part of the variance of the $i$-th forecast variable (in the row) attributed to the $j$-th component of the shock (associated with the variable in the column). As notation we denote by Ret to mean returns and Volat to mean volatility.

\begin{tabular}{|c|c|c|c|c|c|c|}
\hline & Ret bonds & Ret stocks & Volat bonds & Volat stocks & Spread bonds & Spread stocks \\
\hline \multicolumn{7}{|c|}{ Forecast horizon 1 } \\
\hline Ret bonds & 0.0000 & 0.0000 & 0.0005 & 0.0000 & 0.0000 & 0.0000 \\
Ret stocks & 0.0000 & 0.0000 & 0.0001 & 0.0000 & 0.0000 & 0.0000 \\
Volat bonds & 0.0005 & 0.0001 & 6.1621 & 0.4433 & 0.0402 & 0.0002 \\
Volat stocks & 0.0000 & 0.0000 & 0.4433 & 0.0319 & 0.0029 & 0.0000 \\
Spread bonds & 0.0000 & 0.0000 & 0.0402 & 0.0029 & 0.0003 & 0.0005 \\
Spread stocks & 0.0000 & 0.0000 & 0.0002 & 0.0000 & 0.0005 & 0.0000 \\
\hline \multicolumn{7}{|c|}{ Forecast horizon 3 } \\
\hline Ret bonds & 0.0000 & 0.0000 & 0.0005 & 0.0000 & 0.0000 & 0.0000 \\
Ret stocks & 0.0000 & 0.0000 & 0.0004 & 0.0000 & 0.0000 & 0.0000 \\
Volat bonds & 0.0005 & 0.0004 & 5.8370 & 0.3658 & 0.0169 & 0.0001 \\
Volat stocks & 0.0000 & 0.0000 & 0.3658 & 0.0229 & 0.0011 & 0.0000 \\
Spread bonds & 0.0000 & 0.0000 & 0.0169 & 0.0011 & 0.0000 & 0.0000 \\
Spread stocks & 0.0000 & 0.0000 & 0.0001 & 0.0000 & 0.0000 & 0.0000 \\
\hline \multicolumn{7}{|c|}{ Forecast horizon 6} \\
\hline Ret bonds & 0.0000 & 0.0000 & 0.0004 & 0.0000 & 0.0000 & 0.0000 \\
Ret stocks & 0.0000 & 0.0000 & 0.0001 & 0.0000 & 0.0000 & 0.0000 \\
Volat bonds & 0.0004 & 0.0001 & 5.9890 & 0.0422 & 0.0160 & 0.0000 \\
Volat stocks & 0.0000 & 0.0000 & 0.0422 & 0.0003 & 0.0001 & 0.0000 \\
Spread bonds & 0.0000 & 0.0000 & 0.0160 & 0.0001 & 0.0000 & 0.0000 \\
Spread stocks & 0.0000 & 0.0000 & 0.0000 & 0.0000 & 0.0000 & 0.0000 \\
\hline \multicolumn{7}{|c|}{ Forecast horizon 9 } \\
\hline Ret bonds & 0.0000 & 0.0000 & 0.0003 & 0.0000 & 0.0000 & 0.0000 \\
Ret stocks & 0.0000 & 0.0000 & 0.0001 & 0.0000 & 0.0000 & 0.0000 \\
Volat bonds & 0.0003 & 0.0001 & 6.1552 & 0.4730 & 0.0056 & 0.0004 \\
Volat stocks & 0.0000 & 0.0000 & 0.4730 & 0.0364 & 0.0004 & 0.0000 \\
Spread bonds & 0.0000 & 0.0000 & 0.0056 & 0.0004 & 0.0000 & 0.0000 \\
Spread stocks & 0.0000 & 0.0000 & 0.0004 & 0.0000 & 0.0000 & 0.0000 \\
\hline \multicolumn{7}{|c|}{ Forecast horizon 12} \\
Ret bonds & 0.0000 & 0.0000 & 0.0004 & 0.0000 & 0.0000 & 0.0000 \\
Volat bonds & 0.0000 & 0.0000 & 0.0003 & 0.0000 & 0.0000 & 0.0000 \\
Volat stocks & 0.0000 & 0.0003 & 5.7486 & 0.5309 & 0.0284 & 0.0003 \\
Spread bonds & 0.0000 & 0.0000 & 0.5309 & 0.0490 & 0.0026 & 0.0000 \\
Spread stocks & 0.0000 & 0.0000 & 0.0284 & 0.0026 & 0.0001 & 0.0000 \\
\hline
\end{tabular}

